DIW BERLIN

Discussion

Papers

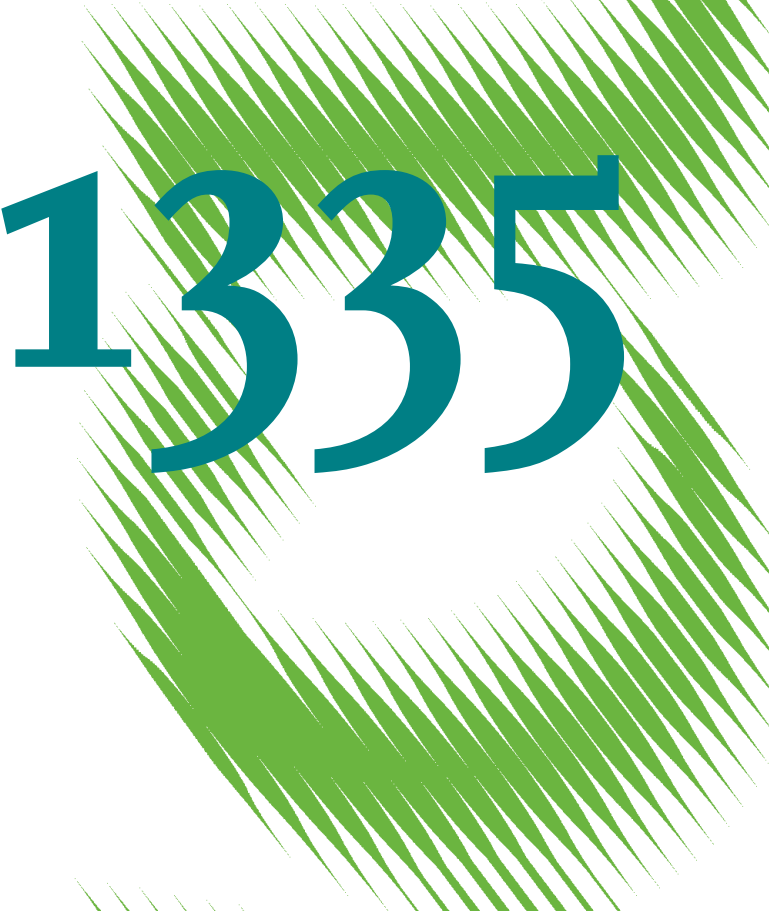

Price Guarantees, Consumer Search, and Hassle Costs 
Opinions expressed in this paper are those of the author(s) and do not necessarily reflect views of the institute.

IMPRESSUM

(C) DIW Berlin, 2013

DIW Berlin

German Institute for Economic Research

Mohrenstr. 58

10117 Berlin

Tel. $+49(30) 89789-0$

Fax +49 (30) $89789-200$

http://www.diw.de

ISSN print edition $1433-0210$

ISSN electronic edition 1619-4535

Papers can be downloaded free of charge from the DIW Berlin website:

http://www.diw.de/discussionpapers

Discussion Papers of DIW Berlin are indexed in RePEc and SSRN:

http://ideas.repec.org/s/diw/diwwpp.html

http://www.ssrn.com/link/DIW-Berlin-German-Inst-Econ-Res.html 


\title{
Price Guarantees, Consumer Search, and Hassle Costs
}

\author{
Pio Baake* and Ulrich Schwalbe ${ }^{\dagger}$
}

November 2013

\begin{abstract}
The paper deals with the competitive effects of price guarantees in a spatial duopoly where consumers can search for lower prices but have to incur hassle costs if they want to claim a price guarantee. It is shown that symmetric equilibria with and without price guarantees exist but price guarantees will have no effect on prices if search costs are low, hassle costs are high and the number of uninformed consumers is small. However, when both firms use price guarantees, there also exist payoff-dominant equilibria where both firms use mixed pricing strategies in the form of "high-low" pricing schemes, provided that the search costs are sufficiently high.
\end{abstract}

Keywords: Price Matching Guarantees, Search Costs, Oligopoly Pricing

JEL-Classification: L11, L13, L15, L41

\section{Introduction}

Price guarantees are a widely used pricing strategy that is employed in various forms in many retail businesses as e.g. hardware, electronics, furniture etc. Price guarantees take different forms and may differ with respect to the details of the guarantee. A price guarantee in the form of a "meeting competition clause" promises each buyer to pay out the difference between the price charged in the shop granting the guarantee, and the lower price than the one the customer has found in a different shop. A variant of this type, mainly used in the context of long term contracts, is a "meet or release clause" where the

\footnotetext{
*Deutsches Institut für Wirtschaftsforschung, Berlin, email: pbaake@diw.de

${ }^{\dagger}$ Department of Economics, University of Hohenheim, Stuttgart, email: ulrich.schwalbe@unihohenheim.de
} 
customer can either cancel a contract at no cost if he has found a contract with lower payments, and/or the conditions of the better contract are met. Another form of a price guarantee is the "beating competition clause", or price beating guarantee, that promises to repay any price difference plus a fixed amount or plus a percentage of the price difference. Sometimes price guarantees are granted only when certain conditions are met, e.g. that internet dealers are excluded from the price guarantee, that price guarantees apply only to the advertised price that is displayed or announced in an advertisement by a competitor or to the actual selling price, or that a lower price has to be presented within a certain time period after the purchase. ${ }^{1}$

Our paper aims at integrating different aspects of price guarantees that have been discussed in the literature: We consider a simple spatial duopoly model with differentiated products where some consumers have only limited information about the prices charged in the market, i.e. they observe only one price. These consumers can gather additional price information which, however, is costly. The signalling role of price guarantees is not considered in our model since we assume identical firms. The setup of the model is closely related to the work of Moorthy/Winter (2006) on the one hand and the contributions by Mao (2005) and Jannsen/Parakhonyak (2010) on the other but integrates the different aspects into one coherent framework. First, we allow for consumer search in a similar fashion as in Mao (2005) and in Jannsen/ Parakhonyak (2010). Second, we consider the fact that claiming a price guarantee incurs some cost (hassle cost). Third, we allow for the firms to use a mixed strategy with respect to their pricing decision in a form that is known as a "high-low" pricing strategy where firms change their prices at irregular intervals by switching between two prices, the higher regular price and the lower sales price. This type of pricing behaviour is described in the marketing literature but is also empirically observed, e.g. in the food retail business (see e.g. Pesendorfer (2002)). It has also been noticed by competition authorities. ${ }^{2}$ In this framework, we confirm the anticompetitive effects of price guarantees under certain conditions on search and hassle costs. We

\footnotetext{
${ }^{1}$ For recent surveys on the economic literature on price guarantees c.f. Arnold/Schwalbe (2009), Hviid (2010), and Winter (2008).

${ }^{2}$ In a merger case of two large grocery chains, the German competition authority has carried out an empirical examination of the pricing behaviour of several products. It has found the "high-low" pricing behaviour to be a common feature. C.f. Bundeskartellamt B2 333/07.
} 
also demonstrate that the use of mixed strategies with respect to prices, i.e. a "high-low" pricing strategy, yields higher profits for the firms.

Our paper is organized as follows. In section two, we give a short review of the literature on price guarantees. In section three a duopoly model of price guarantees that allows for hassle costs as well as imperfect information on the side of consumers is spelled out. Section four analyses the equilibria in the game with and without price guarantees, and with pure and mixed pricing strategies. Section five concludes.

\section{Literature Review}

Economic theory has been dealing with price guarantees for some time and has discussed several reasons why price guarantees are employed by firms. The first reason why firms might use a price guarantee has been pointed out by Salop (1981) who demonstrated that price meeting guarantees can be used in oligopolistic industries as a facilitating practice that makes it easier for the oligopolists to establish and to stabilize tacitly collusive behaviour. If firms in an industry grant price meeting guarantees, the incentive to deviate from the coordinated equilibrium will be reduced. A firm that deviates from the coordinated price cannot gain additional profit, since all other firms immediately charge the same price, because of the price guarantee. In addition, market transparency is increased since customers will keep other firms informed if there is a deviation from the coordinated price. This argument has been formally analysed and extended in several directions in the work by Arbatskaya (2001), Baye/Kovenock (1994), Belton (1987), Doyle (1988), Edlin (1997), Edlin/Emch (1999), Holt/Scheffman (1987), Logan/Lutter (1989), Lu/Wright (2010), Sargent (1993), Schnitzer (1994), Zhang (1995) among others.

The competitive effects of price beating guarantees have been analysed in particular by Corts (1995), Hviid/Shaffer (1994, 2011) and Kaplan (2000). This literature has pointed out that the effects of a price beating guarantee depend on whether the guarantee refers to the advertised price or to the actual selling price. In the former case, the price beating guarantee does not reduce the incentives to lower the price in an oligopoly while in the

latter, a collusive equilibrium might be stabilized by a price beating guarantee. If costs of using a price guarantee are introduced, Hviid/Shaffer (1999) show that, with these "hassle 
costs", the anticompetitive effects of price guarantees are reduced but not completely eliminated when firms differ e.g. with respect to location.

Moreover, the literature has pointed out that price guarantees can be employed to price discriminate between groups of customers who differ with respect to the price elasticity of their respective demand function, e.g. because they face different costs of acquiring information about the competitor's price. The early literature (Belton (1986), Levy/Gerlowski (1991), Png/Hirshleifer (1987)) has shown, that in a duopolistic equilibrium, price guarantees are an effective way to price discriminate. Uninformed customers pay the higher price while informed customers pay less by claiming the price guarantee. The implications of price guarantees with respect to consumer welfare, however, are ambiguous since one group of customers is favoured while the uninformed customers pay higher prices, as compared to a situation without price guarantees. This literature has been extended by Corts (1996) who shows that, with price beating guarantees, competition for informed consumers becomes very intense, which implies low selling prices. When consumers are differentiated with respect to two dimensions, e.g. the costs of acquiring price information and with respect to store loyalty, Chen et al. (2001) demonstrate that in this case, price guarantees can lead to lower prices and increased consumer welfare.

The third strand of the literature considers the role of price guarantees as an instrument to affect the search behaviour of consumers by credibly signalling that a firm using such a guarantee actually is low priced. In an important paper by Moorthy/Winter (2006) it is shown that this type of signalling can occur in equilibrium in an oligopoly with differentiated products and costly price information, provided that the firms are characterized by significant cost differences and there is a sufficiently large number of informed consumers. However, Moorthy/Winter make no assumption about the incentives for a consumer to gather information and become well informed. The search behaviour of consumers in the presence of price guarantees has been analysed by Mao (2005) and Janssen/Parakhonyak (2010). Mao shows that, with search costs, price guarantees will lead to higher prices than under competition without price guarantees. This supports the anticompetitive role of these pricing strategies. Jannsen/Parakhonyak (2010) show that price guarantees can change a consumer's willingness to pay, in particular if they allow for post-sale search since searching for a lower price at a later date may be considered a valuable option. 
The theoretical literature thus gives the overall impression that the economic effects of price guarantees are mainly anticompetitive, leading to higher prices, higher profits and reduced consumer welfare. However, circumstances can be identified where price guarantees actually lead to lower prices, thus benefiting consumers. This ambiguous role of price guarantees is mirrored in the empirical literature. An early paper by Hess/Gerstner (1991) compares the prices of US supermarkets and shows that the data are consistent with the collusive role of price guarantees. In several studies, Arbatskaya et al. (1999, 2004, 2006) empirically examine the effects of price guarantees. While the first study finds some support for the price-increasing effect of price guarantees, the data in the two other studies are compatible with all three effects mentioned. They also pointed out that the details of a price guarantee are important. Moorthy/Zhang (2006) consider retailers of goods such as electronics, sporting goods, etc. and find some support for the signalling role of price guarantees. Recently, there has also been some experimental research on price guarantees, in particular with respect to its collusion enhancing capacity, e.g. Fatas et al. (2013), Fatas/Manez (2007), Dugar (2007), Mago/Pate (2009) among others. All the experimental results provide a strong support of the anticompetitive, collusion enhancing effects of price guarantees.

\section{The Model}

We consider a spatial duopoly with two symmetric firms, 1 and 2, competing on the unit interval where firm 1 is located at the left endpoint of the interval and firm 2 is positioned at the right endpoint. It is assumed that the firms produce with constant marginal cost which is set equal to zero to simplify the analysis. ${ }^{3}$ Competition is in prices and the firms have to decide simultaneously and independently about the price of the product. In addition, each firm has to decide whether to offer a price guarantee.

We assume a unit mass of consumers where each consumer $\theta \in[0,1]$ buys at most one unit of the product. The consumers are uniformly distributed over the unit interval. A consumer $\theta$ incurs transport costs of $\frac{1}{2} \theta^{2}$ when buying from firm 1 and transport cost of $\frac{1}{2}(1-\theta)^{2}$ when buying from firm 2 . There are also costs of claiming a price guarantee,

\footnotetext{
${ }^{3}$ Positive marginal cost would not lead to a change in the results but would make the calculations more cumbersome.
} 
so called hassle costs of $\gamma \in[0,0.5]$. A price guarantee is defined as a firm's promise to meet any lower price that might be offered by the competitor, i.e. the consumer is paid exactly the price difference. Stated otherwise, we consider price-meeting clauses but not price-beating clauses. ${ }^{4}$

There are two groups of consumers that differ with respect to their information about prices. One group of size $\nu \in(0,1)$ is perfectly informed about the prices charged by the two firms, e.g. by costlessly visiting both locations. Consumers in the other group with size $1-\nu$ observe only the price of the firm that is visited first, i.e. they can visit one firm free of cost and are informed only about the price charged at this location. To acquire information about the price of the other firm, however, the uninformed consumers have to incur a search cost $s \in[0,0.5]$, i.e. we assume that search cost (and hassle cost) cannot be higher than the maximal transport cost. While the informed consumers are characterized by a low opportunity cost of time (normalized to zero) so that they can acquire information about prices in different shops at no cost, the uninformed consumers are characterized by increasing opportunity costs of time, which are zero for collecting the first price information but positive when information about the second price is being gathered.

Both groups are uniformly distributed over the unit interval. A firm can offer a price matching guarantee which is observed by both groups of consumers. The assumption can be justified by the fact that shops often advertise the fact that they offer price guarantees, for example in the internet, but do not advertise the prices. A consumer that is perfectly informed about the prices and the price guarantees will base his decision where to buy on the prices charged by the two firms, the price guarantees, the transport costs and the hassle costs. Consumers with imperfect information about the prices decide where to buy depending on their expectation of the unobserved price, the price guarantees, transport, search and hassle cost. We assume that the consumers' willingness to pay for the good is sufficiently high compared to prices and costs such that every consumer buys a unit, i.e. that the market is fully covered.

The timing structure of the game is as follows. First, the two firms decide whether to offer a price guarantee, and what price to charge for their product. Secondly, all consumers are

\footnotetext{
${ }^{4}$ For a recent model that discusses both types of price guarantees in one model, see Hviid et al. (2012).
} 
informed whether or not the firms offer a price guarantee. A fraction $\nu$ of the consumers is also informed about the prices charged by both firms. The remaining uninformed consumers $(1-\nu)$ are informed only about the price of the firm visited. Thirdly, given their information, consumers decide where to buy, whether to search and whether to claim the price guarantee in case such a guarantee is offered. To solve the game we concentrate on fulfilled expectations equilibria, where we also assume beliefs that expect the equilibrium strategy of a firm when the other firm deviates from the equilibrium path.

\subsection{Consumers}

\subsubsection{Informed Consumers}

An informed consumer $\theta$ incurs the following costs when buying from firm located at $i, j \in\{1,2\}, j \neq i$ (where $\lambda_{i}=0$ for $i=1$ and $\lambda_{i}=1$ for $i=2$ ):

$$
\begin{array}{ll}
c_{i}\left(p_{i}\right)=p_{i}+\frac{1}{2}\left(\lambda_{i}-\theta\right)^{2} & \text { PG not offered } \\
c_{i}^{G}\left(p_{i}, p_{j}\right)=\left(p_{j}+\gamma\right)+\frac{1}{2}\left(\lambda_{i}-\theta\right)^{2} & \text { PG offered and used }
\end{array}
$$

Here, $c_{i}$ denotes the cost an informed consumer incurs when firm $i$ does not offer a price guarantee. Similarly, $c_{i}^{G}$ denotes the cost a consumer incurs when firm $i$ offers a price guarantee which is used by the consumer. Obviously, using the price guarantee is worthwhile only if $p_{i}-p_{j} \geq \gamma$.

Defining

$$
c_{i}^{I}\left(p_{i}, p_{j}\right)= \begin{cases}c_{i}\left(p_{i}\right) & \text { if firm } i \text { does not offer PG } \\ \min \left\{c_{i}\left(p_{i}\right), c_{i}^{G}\left(p_{i}, p_{j}\right)\right\} & \text { if firm } i \text { offers a PG }\end{cases}
$$

an informed consumer is indifferent between buying at firm 1 or firm 2 if the following condition is satisfied:

$$
\theta^{I}(\cdot)=\frac{1}{2}+\Delta^{I}(\cdot) \text { with } \Delta^{I}(\cdot):=c_{2}^{I}\left(p_{2}, p_{1}\right)-c_{1}^{I}\left(p_{1}, p_{2}\right)
$$

where the superscript $I$ stands for 'informed'. Notice that the location of an indifferent consumer depends on the respective subgame, i.e. whether both firms, only one firm or no 
firm offer a price guarantee.

\subsubsection{Uninformed Consumers}

To analyse the decision of uninformed consumers, note first that after going to firm $i$ first, an uninformed consumer has essentially three options: Either he buys from firm $i$ without any search, or he searches and buys from the firm where the actual costs are lower. If firm $i$ offers a PG, the consumer can also decide to search and to use the PG. Given the observed price $p_{i}$, the expected costs for these options can be written as (where $\mu_{i}=1$ for $i=1$ and $\mu_{i}=-1$ for $\left.i=2\right)$

no search:

$c_{i}^{E}\left(p_{i}\right)=p_{i}+\frac{1}{2}\left(\lambda_{i}-\theta\right)^{2}$

search and switching:

$c_{i}^{E S}\left(p_{i}, \cdot\right)=\left\{\begin{array}{l}\operatorname{Pr}\left\{p_{i} \leq p_{j}+\mu_{i}\left(\frac{1}{2}-\theta\right)\right\}\left(p_{i}+\frac{1}{2}\left(\lambda_{i}-\theta\right)^{2}\right) \\ +\operatorname{Pr}\left\{p_{i} \geq p_{j}+\mu_{i}\left(\frac{1}{2}-\theta\right)\right\}\left(E\left[p_{j} \mid p_{i} \geq p_{j}+\mu_{i}\left(\frac{1}{2}-\theta\right)\right]+\frac{1}{2}\left(\lambda_{j}-\theta\right)^{2}\right)+s\end{array}\right.$

search and use of PG:

$c_{i}^{E G}\left(p_{i}, \cdot\right)=\left\{\begin{array}{l}\operatorname{Pr}\left\{p_{i} \leq p_{j}+\gamma\right\}\left(p_{i}+\frac{1}{2}\left(\lambda_{i}-\theta\right)^{2}\right) \\ +\operatorname{Pr}\left\{p_{i} \geq p_{j}+\gamma\right\}\left(E\left[p_{j} \mid p_{i} \geq p_{j}+\gamma\right]+\gamma+\frac{1}{2}\left(\lambda_{i}-\theta\right)^{2}\right)+s .\end{array}\right.$

Similar to the case of informed consumers, $c_{i}^{E}$ denotes the cost without search. The expected $\operatorname{costs} c_{i}^{E S}$ with search and switching consist of three parts: First, the cost of buying at firm $i$ weighted with the probability that $p_{i}$ is not high enough to induce the consumer to switch to firm $j$. Second, the cost of buying at firm $j$ which consists of the expected price $p_{j}$ and the transport cost weighted with the probability that buying from firm $j$ is optimal, and finally the search cost $s$.

The expected cost $c_{i}^{E G}$ when firm $i$ offers a PG also consists of three parts: First, the price charged by firm $i$ plus the transport cost weighted by the probability that the price difference between $p_{i}$ and $p_{j}$ is smaller than the cost of using the price guarantee. Second, the expected price of firm $j$ conditional on the price difference between $p_{i}$ and $p_{j}$ is larger 
than the hassle cost plus the hassle and the transport costs, all weighted with the probability that the price difference between $p_{i}$ and $p_{j}$ is larger than the hassle cost. Finally, the expected cost depends on the search cost $s$.

Defining

$$
c_{i}^{N I}\left(p_{i}, \cdot\right)= \begin{cases}\min \left\{c_{i}^{E}\left(p_{i}, \cdot\right), c_{i}^{E S}\left(p_{i}, \cdot\right)\right\} & \text { if firm } i \text { does not offer PG } \\ \min \left\{c_{i}^{E}\left(p_{i}, \cdot\right), c_{i}^{E S}\left(p_{i}, \cdot\right), c_{i}^{E G}\left(p_{i}, \cdot\right)\right\} & \text { if firm } i \text { offers a PG }\end{cases}
$$

where the superscript $N I$ stands for 'uninformed'. Taking expectations, an uninformed consumer is indifferent between going first to firm 1 or firm 2 if the following condition is satisfied:

$$
\theta^{N I}(\cdot)=\frac{1}{2}+\Delta^{N I}(\cdot) \text { with } \Delta^{N I}(\cdot):=E\left[c_{2}^{N I}\left(p_{2}, \cdot\right)\right]-E\left[c_{1}^{N I}\left(p_{1}, \cdot\right)\right]
$$

In the next section, we derive the fulfilled expectations equilibria of the game. We start by analysing the four subgames that might arise in the game: First, the subgame where no firm offers a price guarantee, secondly, the subgame where both firms offer a price guarantee and use either pure or mixed strategies in the form of a "high-low" pricing strategy. Finally, we consider the subgames where only one firm offers a price guarantee. This allows us to compute the equilibria of the overall game.

\section{Equilibria}

\subsection{Equilibrium in the subgame without price guarantees}

We derive a symmetric equilibrium where both firms $i, j=1,2, i \neq j$ choose a price $p^{*}$. To simplify the exposition we focus on the case where both firms use a pure strategy such that uninformed consumers do not search and buy from the firm they visit first. We show in appendix B that equilibria where firms use mixed strategies and uninformed consumers may search do not exist. ${ }^{5}$

Assume that firms choose prices $p_{1}$ and $p_{2}$, respectively. For informed consumers being

\footnotetext{
${ }^{5}$ Notice that we do not intend to characterize the equilibrium set of this game but concentrate on the analysis of pure strategies and a special type of mixed strategies.
} 
indifferent between buying at firm 1 or firm 2 and uninformed consumers being indifferent between going to firm 1 or firm 2 first, (3) and (8) simplify to

$$
\theta^{I}(\cdot)=\frac{1}{2}+p_{2}-p_{1} \text { and } \theta^{N I}(\cdot)=\frac{1}{2}+p_{2}^{E}-p_{1}^{E}
$$

The profits of the two firms are given by

$$
\begin{aligned}
& \pi_{1}\left(p_{1}, \cdot\right)=p_{1}\left[\nu \theta^{I}(\cdot)+(1-\nu) \theta^{N I}(\cdot)\right] \\
& \pi_{2}\left(\cdot, p_{2}\right)=p_{2}\left[\nu\left(1-\theta^{I}(\cdot)\right)+(1-\nu)\left(1-\theta^{N I}(\cdot)\right)\right] .
\end{aligned}
$$

In a fulfilled expectation equilibrium, the prices chosen by each firm have to be mutually best replies given the strategy, i.e. the price charged by the other firm, and the beliefs have to be confirmed.

Using (9) and taking into account the fulfilled expectations condition $p_{i}^{E}=p_{i}$, the first order conditions are given by

$$
\frac{\partial \pi_{1}(\cdot)}{\partial p_{1}}=\frac{1}{2}-(1+\nu) p_{1}+p_{2}=0 \text { and } \frac{\partial \pi_{2}(\cdot)}{\partial p_{2}}=\frac{1}{2}-(1+\nu) p_{2}+p_{1}=0
$$

The second order conditions for a profit maximum are satisfied as

$$
\frac{\partial^{2} \pi_{i}(\cdot)}{\partial p_{i}^{2}}=-2 \nu<0 \quad i=1,2
$$

Thus, the first order conditions imply that there is a unique symmetric solution. The result is summarized in the following lemma.

Lemma 1 In the subgame where no firm offers a price guarantee, the unique symmetric equilibrium prices are given by $p_{i}^{*}=p^{*}=\frac{1}{2 \nu}$ and the equilibrium profits are $\pi_{i}^{*}=\frac{1}{4 \nu}$.

Proof. See appendix A.

Notice that equilibrium prices and profits are positively correlated with the number of uninformed consumers in the market. The larger the fraction of uninformed consumers in the market, the higher the firms' prices and profits, i.e. the lack of information is exploited by the firms. 


\subsection{Equilibria in the subgames where only one firm offers a price guar- antee}

Consider a situation where only one firm, say firm 1, offers a price guarantee and assume that firms choose prices $p_{1}$ and $p_{2}$, respectively, such that informed consumers do not use the price guarantee and that uninformed consumers do not search. Then, price guarantees do not change the behavior of consumers' in the first place and we again get

$$
\theta^{I}(\cdot)=\frac{1}{2}+p_{2}-p_{1} \text { and } \theta^{N I}(\cdot)=\frac{1}{2}+p_{2}^{E}-p_{1}^{E}
$$

Accordingly, analysing the firms' profits and first order conditions we get the same equilibrium prices as in the case without price guarantees. However, offering a price guarantee increases the firm's incentives to deviate from the proposed equilibrium: Deviating by choosing a higher price implies that some informed consumers would use the price guarantee instead of buying from the other firm. Hence, deviations become more profitable if a firm offers price guarantees. More precisely, we show that a pure strategy equilibrium does only exist if the search cost are low enough. Rather high search costs imply that the firm which offers a price guarantee randomizes between a high and low price while the other firm plays a pure strategy.

Starting with pure strategy equilibria we get

Lemma 2 In the subgame where only firm 1 offers a price guarantee a symmetric equilibrium in pure strategies with $p_{i}^{*}=p^{*}=\frac{1}{2 \nu}$ and $\pi_{i}^{*}=\frac{1}{4 \nu}$ exists as long as $s \leq s^{P}(\gamma, \nu):=$ $\gamma /(1-\nu)$.

Proof. See appendix A.

For sufficiently high search costs the pure strategy equilibrium just analyzed does not exist. To construct a mixed strategy equilibrium we consider a special type of strategy where the firm offering the price guarantee, i.e. firm 1, randomizes between a high "regular" price, denoted by $\bar{p}_{1}$ and a low "sales" price, denoted by $\underline{p}_{1}$. The probabilities that firm 1 chooses the high price, $\operatorname{Pr}\left(p_{1}=\bar{p}_{1}\right)$ is denoted by $\rho_{1}$ and the probability that the low price

is charged, $\operatorname{Pr}\left(p_{1}=\underline{p}_{1}\right)$ is accordingly $1-\rho_{1}$. Firm 2 plays a pure strategy. Furthermore, we concentrate on the case where the price guarantee is only used if the high price is charged 
by firm 1, i.e. $\bar{p}_{1}-p_{2}>\gamma>\underline{p}_{1}-p_{2}$, and where uninformed consumers do not search if they observe the high price. ${ }^{6}$

Using these assumptions, the demand of informed consumers at firm 1 is given by

$$
\theta^{I}(\cdot)=\left\{\begin{array}{lll}
\frac{1}{2}+p_{2}-p_{1} & \text { if } & p_{1}=\underline{p}_{1} \\
\frac{1}{2}-\gamma & \text { if } & p_{1}=\bar{p}_{1}
\end{array}\right.
$$

Considering uninformed consumers, (8) can be written as

$$
\theta^{N I}(\cdot)=\frac{1}{2}+p_{2}^{E}-\rho_{1}^{E} \bar{p}_{1}^{E}+\left(1-\rho_{1}^{E}\right) \underline{p}_{1}^{E}
$$

where $\rho_{1}^{E}$ denotes the expected probability that firm 1 chooses the high price $\bar{p}_{1}^{E}$. Note that $\theta^{N I}(\cdot)$ is only determined by the consumers' expectation. This is due to our assumption that observing the high price does not induce an uninformed to search.

The profit of firm 1 when it charges the regular (high) price is given by

$$
\pi_{1}\left(\bar{p}_{1}, p_{2}, \cdot\right)=p_{2} \nu\left(\frac{1}{2}-\gamma\right)+\bar{p}_{1}(1-\nu) \theta^{N I}(\cdot)
$$

When firm 1 charges the sales price, its profit is given by

$$
\pi_{1}\left(\underline{p}_{1}, p_{2}, \cdot\right)=\underline{p}_{1}\left[\nu\left(\frac{1}{2}+p_{2}-\underline{p}_{1}\right)+(1-\nu) \theta^{N I}(\cdot)\right]
$$

Expected profits or firm 2 can written as

$$
E \pi_{2}\left(p_{2}, \cdot\right)=p_{2}\left[\nu\left(\rho_{1}\left(\frac{1}{2}-\gamma\right)+\left(1-\rho_{1}\right)\left(\frac{1}{2}+p_{2}-\underline{p}_{1}\right)\right)+(1-\nu)\left(1-\theta^{N I}\right)(\cdot)\right]
$$

To compute the fulfilled expectation equilibrium of the subgame, the following equilibrium conditions have to be satisfied. First, the prices of the firms have to be mutually best replies, i.e.

$$
\frac{\partial \pi_{1}\left(\bar{p}_{1}, \cdot\right)}{\partial \bar{p}_{1}} \geq 0 \text { for } \bar{p}_{1}=p_{2}+s, \frac{\partial \pi_{1}\left(\underline{p}_{1}, \cdot\right)}{\partial \underline{p}_{1}}=0 \quad \text { and } \quad \frac{\partial E \pi_{2}\left(p_{2}, \cdot\right)}{\partial p_{2}}=0 .
$$

\footnotetext{
${ }^{6}$ If the low price were higher than $p_{2}+\gamma$, both prices of firm 1 would be higher than $p_{2}$ which cannot be an equilibrium.
} 
Secondly, expectations have to be fulfilled in equilibrium.

$$
\bar{p}_{1}^{E}=\bar{p}_{1} ; \underline{p}_{1}^{E}=\underline{p}_{1} ; p_{2}^{E}=p_{2} \text { and } \rho_{1}^{E}=\rho_{1}
$$

Thirdly, if a mixed strategy is used, firm 1 has to be indifferent between the high and the low price,

$$
\pi_{1}\left(\bar{p}_{1}, \cdot\right)=\pi_{1}\left(\underline{p}_{1}, \cdot\right)
$$

Finally, the price guarantee is used only if firm 1 charges the high price, i.e. $\bar{p}_{1}-p_{2}>\gamma>$ $\underline{p}_{1}-p_{2}$. Analyzing these conditions we obtain

Lemma 3 In the subgame where only firm 1 offers a price guarantee and $s>s^{P}(\gamma, \nu):=$ $\gamma /(1-\nu)$, a mixed strategy equilibrium exists and is characterized by

$$
\begin{aligned}
& \bar{p}_{1}=p_{2}+s \\
& \underline{p}_{1}=\frac{2\left(1-\rho_{1}\right)+\nu\left(1+2 \rho_{1}\left(\gamma\left(1-(1-\nu) \rho_{1}\right)-\left(1-\nu-2 \rho_{1}(1-\nu)\right) s\right)\right)}{2 \nu\left(1-\rho_{1}\right)\left(2+\nu-(1-\nu) \rho_{1}\right)} \\
& p_{2}-\underline{p}_{1}=\frac{\rho_{1}\left(1+2 \gamma \nu+2(1-\nu)\left(2-\rho_{1} s\right)\right.}{2 \nu\left(1-\rho_{1}\right)\left(2+\nu-(1-\nu) \rho_{1}\right)}>0
\end{aligned}
$$

and $\rho_{1}$ such that $\pi_{1}\left(\bar{p}_{1}, \cdot\right)=\pi_{1}\left(\underline{p}_{1}, \cdot\right)$.

Proof. See appendix A.

Let $E \pi_{1}^{*}=\pi_{1}\left(\bar{p}_{1}, \cdot\right)=\pi_{1}\left(\underline{p}_{1}, \cdot\right)$ denote the equilibrium profit of firm 1 in the mixed strategy equilibrium. Comparing this profit with the profit firms get if no firm offers price guarantees we obtain

Corollary 1 A mixed strategy equilibrium yields higher profits for the firm which uses price guarantees, i.e.

$$
E \pi_{1}^{*}>\pi^{*}
$$

Proof. See appendix A.

The different types of equilibria are shown in figure 1. 

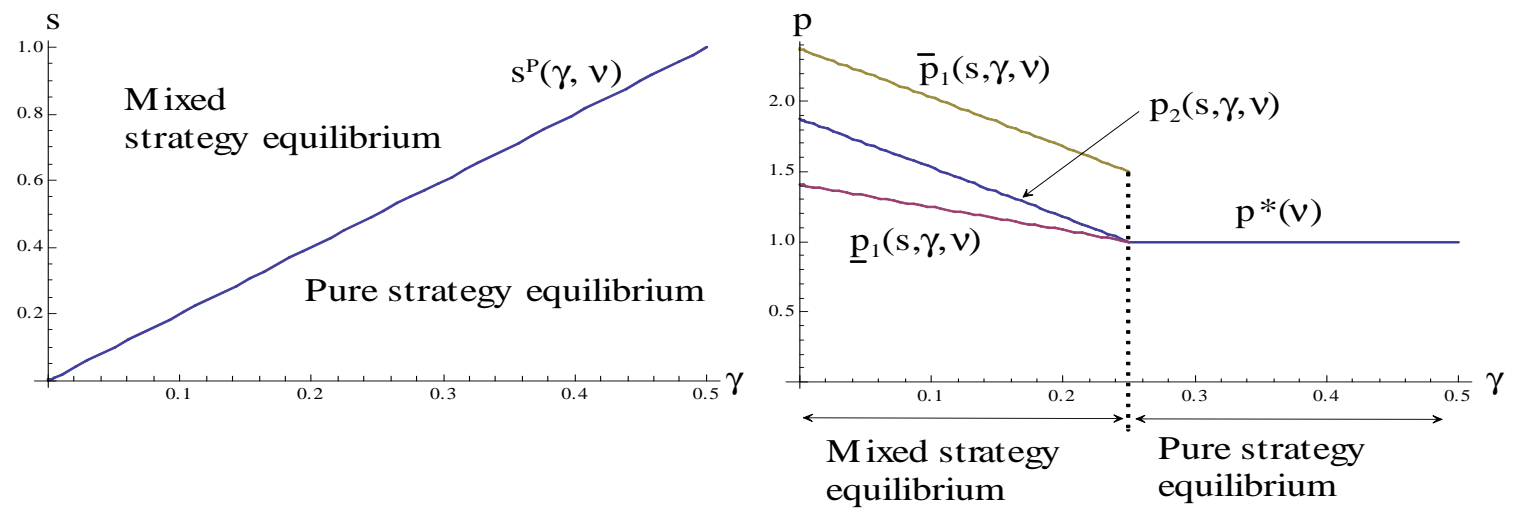

Figure 1: Equilibria in mixed and pure strategies (prices for $s=\nu=0.5$ )

On the left side two different areas with equilibria in pure and mixed strategies are displayed. For a given value of $\nu$ a pure strategy equilibrium exists if the search $\operatorname{costs} s$ are low in relation to the hassle costs $\gamma$. In this case, prices and profits are the same as in the case where no firm offers a price guarantee, i.e. for high values of $\gamma$, price guarantees have no impact on the market outcome. When search costs are high in relation to hassle costs, however, the firm that offers a price guarantee mixes between two prices, a high regular price and a low sales price as shown in the right hand figure. Notice that for given levels of $\nu$ and $s$, the spread between the two prices is a decreasing function of the hassle costs and the uniform price charged by the firm that does not offer a price guarantee is between the regular and the sales price and also decreases in the hassle costs.

\subsection{Equilibria in the subgame with price guarantees}

The analysis of the subgame where both firms offer price guarantees is similar to the case where only one firm offers a price guarantee. It turns out that equilibria in pure as well as in mixed strategies exist, depending on the level of search and hassle costs as well as the ratio of the uninformed consumers. We consider pure strategy equilibria first.

Applying the same reasoning as in the subgame where only one firm offers a price guarantee we immediately get

Lemma 4 In the subgame where both firms offer price guarantees and use pure strategies with respect to prices, the prices and profits in a symmetric equilibrium are given by $p_{i}^{* *}=$ $p^{*}=\frac{1}{2 \nu}$ and $\pi_{i}^{* *}=\pi_{i}^{*}=\frac{1}{4 \nu}$ provided that $s \leq s^{P}(\gamma, \nu)$. 
Proof. See appendix A.

If, for a given ratio of uninformed consumers, the hassle costs are sufficiently higher than the search costs, the introduction of price guarantees has no effect on the equilibrium prices. The market outcome is the same as in the situation without price guarantees. This generalizes the result of Hviid/Shaffer (1999) who show that in a situation with symmetric firms and without search costs, even arbitrarily low hassle costs will eliminate the anticompetitive effects of price guarantees.

However, if the search costs are sufficiently high or if the hassle costs are very low, there is only an equilibrium in mixed strategies as shown in the next paragraph.

To show that for sufficiently high search costs there exists an equilibrium in mixed strategies, we again focus on mixed strategies with respect to prices where firm $i$ has a choice between a high "regular" price, denoted by $\bar{p}_{i}$ and a low "sales" price, denoted by $\underline{p}_{i}$. The probabilities that firm $i$ chooses the high price, $\operatorname{Pr}\left(p_{i}=\bar{p}_{i}\right)$ is denoted by $\rho_{i}$ and the probability that the low price is charged, $\operatorname{Pr}\left(p_{i}=\underline{p}_{i}\right)$ is accordingly $1-\rho_{i}$.

In the subgame we consider, both firms offer a price guarantee and to exclude the case where a price guarantee is never used, we assume that $\bar{p}_{i}-\underline{p}_{j}>\gamma$. Furthermore, we consider only the case where uninformed consumers do not search if they observe the high price and analyze symmetric equilibria only. ${ }^{7}$

The demand of informed consumers at firm 1 is given by (see (3))

$$
\theta^{I}(\cdot)=\left\{\begin{array}{lll}
\frac{1}{2}+\gamma & \text { if } & p_{1}=\underline{p}_{1}<p_{2}=\bar{p}_{2} \\
\frac{1}{2}-\gamma & \text { if } & p_{1}=\bar{p}_{1}>p_{2}=\underline{p}_{2} \\
\frac{1}{2}+p_{2}-p_{1} & \text { otherwise } &
\end{array}\right.
$$

If the product is on sale only at firm 1 , additional consumers are attracted that have high costs (hassle as well as travelling costs) to claim the price guarantee at firm 2 and vice versa if it is on sale only at firm 2 . If both firms charge the same price (either regular or sale), demand of the informed consumers is split evenly.

\footnotetext{
${ }^{7}$ Our focus on symmetry is justified by lemma 6 of Dasgupta/Maskin (1986). Furthermore, we show in appendix B that a mixed strategy equilibrium where uninformed consumers may search does not exist.
} 
Considering uninformed consumers, (8) can be written as

$$
\theta^{N I}(\cdot)=\frac{1}{2}+\rho_{2}^{E} \bar{p}_{2}^{E}+\left(1-\rho_{2}^{E}\right) \underline{p}_{2}^{E}-\rho_{1}^{E} \bar{p}_{1}^{E}+\left(1-\rho_{1}^{E}\right) \underline{p}_{1}^{E}
$$

where $\rho_{i}^{E}$ denotes the expected probability that firm $i$ chooses the high price $\bar{p}_{i}^{E}$. Note that $\theta^{N I}(\cdot)$ is only determined by the consumers' expectation. This is due to our assumption that observing the high price does not induce an uninformed to search.

The expected profits of firm 1 when it charges the regular price is given by (analogous expressions apply for firm 2)

$$
\begin{gathered}
E \pi_{1}\left(\bar{p}_{1}, \cdot\right)=\rho_{2} \pi_{1}\left(\bar{p}_{1}, \bar{p}_{2}, \cdot\right)+\left(1-\rho_{2}\right) \pi_{1}\left(\bar{p}_{1}, \underline{p}_{2}, \cdot\right) \\
\text { with } \pi_{1}\left(\bar{p}_{1}, \bar{p}_{2}, \cdot\right)=\bar{p}_{1}\left[\nu\left(\frac{1}{2}+\bar{p}_{2}-\bar{p}_{1}\right)+(1-\nu) \theta^{N I}(\cdot)\right] \\
\quad \text { and } \pi_{1}\left(\bar{p}_{1}, \underline{p}_{2}, \cdot\right)=\underline{p}_{2} \nu\left(\frac{1}{2}-\gamma\right)+\bar{p}_{1}(1-\nu) \theta^{N I}(\cdot)
\end{gathered}
$$

When firm 1 charges the sales price, expected profits are given by

$$
\begin{aligned}
& E \pi_{1}\left(\underline{p}_{1}, \cdot\right)=\rho_{2} \pi_{1}\left(\underline{p}_{1}, \bar{p}_{2}, \cdot\right)+\left(1-\rho_{2}\right) \pi_{1}\left(\underline{p}_{1}, \underline{p}_{2}, \cdot\right) . \\
& \text { with } \pi_{1}\left(\underline{p}_{i}, \bar{p}_{2}, \cdot\right)=\underline{p}_{1}\left[\nu\left(\frac{1}{2}+\gamma\right)+(1-\nu) \theta^{N I}(\cdot)\right] \\
& \text { and } \pi_{1}\left(\underline{p}_{1}, \underline{p}_{2}, \cdot\right)=\underline{p}_{1}\left[\nu\left(\frac{1}{2}+\underline{p}_{2}-\underline{p}_{1}\right)+(1-\nu) \theta^{N I}(\cdot)\right]
\end{aligned}
$$

To compute the fulfilled expectation equilibrium of the subgame, the following equilibrium conditions have to be satisfied. First, the regular and the sales prices have to be mutually best replies, i.e.

$$
\frac{\partial E \pi_{i}\left(\underline{p}_{i}, \cdot\right)}{\partial \underline{p}_{i}}=0 \quad \text { and } \quad \frac{\partial E \pi_{i}\left(\underline{p}_{i}, \cdot\right)}{\partial \bar{p}_{i}}=0 .
$$

Secondly, expectations have to be fulfilled in equilibrium.

$$
\bar{p}_{i}^{E}=\bar{p}_{i} ; \quad \text { and } \quad \underline{p}_{i}^{E}=\underline{p}_{i} ; \rho_{i}^{E}=\rho_{i}
$$

Thirdly, if a mixed strategy is used, the firms have to be indifferent between the regular and the sales price, $E \pi_{i}\left(\underline{p}_{i}, \cdot\right)=E \pi_{i}\left(\bar{p}_{i}, \cdot\right)$ and finally, the price guarantee is used if only one firm charges the sales price, $\bar{p}_{i}-\underline{p}_{j}>\gamma$. 
Using (23)-(26) as well as symmetry, i.e. $\bar{p}_{1}=\bar{p}_{2}=\bar{p}, \underline{p}_{1}=\underline{p}_{2}=\underline{p}$ as well as $\rho_{1}=\rho_{2}=\rho$, the first order conditions for the profit maximizing prices are given by

$$
\begin{aligned}
& \frac{\partial E \pi_{i}(\bar{p}, \cdot)}{\partial \bar{p}}=\frac{1}{2}(1-\nu(1-\rho+2 \rho \bar{p}))=0 \\
& \frac{\partial E \pi_{i}(\underline{p}, \cdot)}{\partial \underline{p}}=\frac{1}{2}+\nu(\gamma \rho-\underline{p}(1-r))=0 .
\end{aligned}
$$

The respective second order conditions are satisfied as

$$
\frac{\partial^{2} E \pi_{i}(\underline{p}, \cdot)}{\partial \underline{p}^{2}}=-2 \nu(1-\rho)<0 \quad \text { and } \quad \frac{\partial^{2} E \pi_{i}(\bar{p}, \cdot)}{\partial \bar{p}^{2}}=-2 \nu \rho<0 .
$$

Solving (29) and (30) for the sales price $\underline{p}$ and the regular price $\bar{p}$, respectively, yields

$$
\underline{p}=\frac{1+2 \gamma \nu \rho}{2 \nu(1-\rho)} \quad \text { and } \quad \bar{p}=\frac{1-\nu(1-\rho)}{2 \nu \rho} .
$$

Inserting these prices, the equilibrium profits are given by

$$
E \pi_{i}(\underline{p}, \cdot)=\frac{(1+2 \gamma \nu \rho)^{2}}{4 \nu(1-\rho)}
$$

if the low price is charged and by

$$
E \pi_{i}(\bar{p}, \cdot)=\frac{1+\nu\left(-2+(3-2 \gamma) \rho+\nu\left(1+\rho\left(-2+\rho+2 \gamma \rho-4 \gamma^{2} \rho\right)\right)\right)}{4 \nu \rho}
$$

if the hight price is charged. Since the two pure strategies have to yield the same profits, the probability $\rho$ must satisfy

$$
E \pi_{i}(\underline{p}, \cdot)=E \pi_{i}(\bar{p}, \cdot)
$$

Analyzing (35) leads to

Lemma 5 There exists a unique probability $\rho^{*}(\nu, \gamma) \in(0,1)$ such that $E \pi_{i}(\underline{p}, \cdot)=E \pi_{i}(\bar{p}, \cdot)$ holds.

Proof. See appendix A.

Employing Lemma 5 and considering the properties of $\bar{p}$ and $\underline{p}$ and the implied behaviour of consumers, we obtain that the proposed mixed strategy equilibrium exists if the search 
costs are high enough:

Lemma 6 In the subgame where both firms use price guarantees, there exists an equilibrium in mixed strategies provided that the search costs $s$ is higher than a critical level $s^{M}(\gamma, \nu)$ given by

$$
s^{M}(\gamma, \nu):=\frac{1-2 \rho^{*}(\nu, \gamma)-\nu\left(1-\rho^{*}(\nu, \gamma)\left(2-\rho^{*}(\nu, \gamma)-2 \gamma \rho^{*}(\nu, \gamma)\right)\right)}{2 \nu v \rho^{*}(\nu, \gamma)}
$$

The prices between the firms mix are given by

$$
\underline{p}(\gamma, \nu)=\frac{1+2 \gamma \nu \rho^{*}(\nu, \gamma)}{2 \nu\left(1-\rho^{*}(\nu, \gamma)\right)} \quad \text { and } \quad \bar{p}(\gamma, \nu)=\frac{1-\nu\left(1-\rho^{*}(\nu, \gamma)\right)}{2 \nu \rho^{*}(\nu, \gamma)}
$$

Proof. See appendix A.

For later reference note first, that compared to the case where only one firm offers price guarantees a mixed strategy equilibrium exists for even lower hassle costs. By simple numerical calculations it can be shown that

$$
s^{P}(\gamma, \nu)>s^{M}(\gamma, \nu) \text { for all } \gamma, \nu \in(0,1)
$$

We can also conclude, that profits in a mixed strategy equilibrium with price guarantees are higher than in a pure strategy equilibrium with or without price guarantees and that they increase in $\gamma$ as long as $\gamma$ and $\nu$ are sufficiently small.

Corollary 2 If both firms use price guarantees, the firms' expected profits $E \pi_{i}^{* *}=E \pi^{* *}$ in a mixed strategy equilibrium are given by

$$
E \pi^{* *}(\cdot)=\frac{\left(1+2 \gamma \nu \rho^{*}(\nu, \gamma)\right)^{2}}{4 \nu\left(1-\rho^{*}(\nu, \gamma)\right)}>\frac{1}{4 \nu}=\pi^{*}
$$

Furthermore, comparative statics with respect to $\gamma$ show that $E \pi^{* *}(\cdot)$ increases in $\gamma$ as long as $\gamma$ and $\nu$ are small enough.

Proof. See appendix A.

This could indicate a reason why firms tend to increase the consumers' hassle costs by making it more difficult to claim the price guarantee. 
The different equilibria in the subgame where both firms are offering price guarantees are illustrated in Figure 2. Assuming $\nu=0.5$ and calculating $s^{P}$ as well as $\rho^{*}, s^{M}$ and the respective equilibrium prices we get the graphs depicted in the Figure.
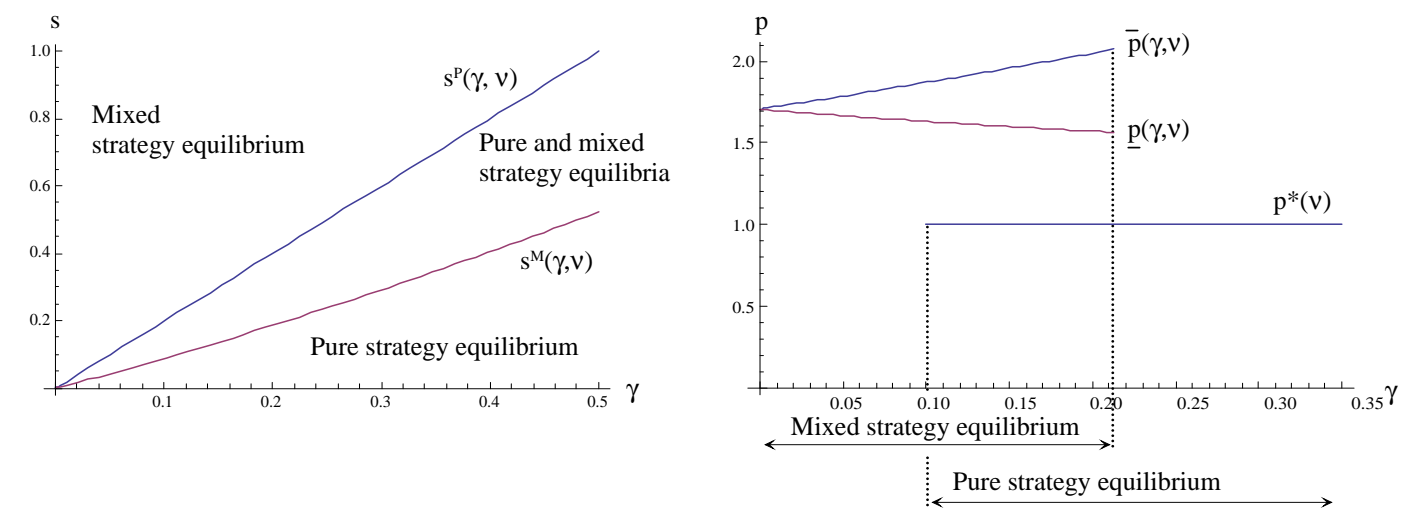

Figure 2: Existence and equilibrium prices for $\nu=0.5$ and $s=0.2$ (for the equilibrium prices)

In the left hand figure the three different areas for the pure and the mixed equilibria are shown as the areas below $s^{M}(\gamma, \nu)$ and above $s^{P}(\gamma, \nu)$. In the region between the two boundaries, pure and mixed equilibria coexist. The figure on the right hand side displays the prices for the three situations. For high values of $\gamma$, only a pure strategy equilibrium exists where the price $p^{*}$ is charged. For intermediate values of the hassle costs, equilibria in pure and mixed strategies coexist. For low values of $\gamma$, only the mixed strategy equilibrium exists with the two prices $\mathrm{p}$ and $\bar{p}$. Notice that the spread between the regular and the sales price is an increasing function of $\gamma$.

Note further, that we have $\bar{p}>\underline{p}>p^{*}$. The intuition for this result is based on the fact that a (small) increase in $p_{1}$ and/or $p_{2}$ does not recude the number of informed consumers buying from either firm 1 or firm 2 as long as either $p_{1}>p_{2}+\gamma$ or $p_{2}>p_{1}+\gamma$ holds. Since this increases the firms' incentives to choose rather high prices, the equilibrium sales price 
$\underline{p}$ is higher than the equilibrium price $p^{*}$ in the pure strategy equilibrium.

\subsection{Equilibrium in the overall game}

After having derived the equilibria in the different subgames, we can now determine the equilibrium in the overall game. Summarizing our above results, the firms' profits do not depend on the use of price guarantees as long as

$$
s^{P}(\gamma, \nu)>s^{M}(\gamma, \nu) \geq s
$$

Hence, for search costs low enough or hassle costs high enough the firms are indifferent between offering price guarantees or not.

For intermediate values of $s$ or $\gamma$, i.e. for

$$
s^{P}(\gamma, \nu) \geq s \geq s^{M}(\gamma, \nu)
$$

there also exist mixed strategy equilibria in the price subgame if both firms offer price guarantees. Employing $E \pi^{* *} \geq \pi^{*}$ it is easy to see that offering price guarantees is a (weakly) dominant strategy: Since $E \pi^{* *}>\pi^{*}$ if the firms play the mixed strategy equilibrium in the price subgame and $\pi^{*}$ if firms play a pure strategy equilibrium, each firm is better off by offering price guarantees (note also that the firms' profits are given by $\pi^{*}$ if only one firm offers price guarantees).

Finally, turning to high search costs and low hassle costs, i.e. to

$$
s>s^{P}(\gamma, \nu)
$$

the equilibrium in the overall game is given by the solution of the following $2 \times 2$ game ( $E \pi_{2}^{*}$ denotes the expected profit of firm 2 if only firm 1 offers price guarantees):

\begin{tabular}{|c|c|c|}
\hline Firm 2 & $P G$ & no $P G$ \\
\hline Firm 1 & & \\
\hline$P G$ & $E \pi^{* *}, E \pi^{* *}$ & $E \pi_{1}^{*}, E \pi_{2}^{*}$ \\
\hline no $P G$ & $E \pi_{2}^{*}, E \pi_{1}^{*}$ & $\pi^{*}, \pi^{*}$ \\
\hline
\end{tabular}


To determine whether the equilibrium is given by $(P G, P G)$ or by either $(P G$, no $P G)$ or (no $P G, P G$ ) we state the following

Result 1 For all $s \geq s^{P}(\gamma, \nu)$, the best reply of firm 2 to $P G$ by firm 1 is to choose $P G$, i.e. $E \pi^{* *}>E \pi_{2}^{*}$.

Proof. See appendix A.

Using this result we can conclude

Proposition 1 If hassle costs are sufficiently low or search costs sufficiently high, the unique equilibrium in the overall game is given by $(P G, P G)$. Otherwise, choosing $P G$ is a weakly dominant strategy. For hassle costs sufficiently high and search costs sufficiently low neither the equilibrium prices nor the firms' profits depend on whether the firms offer price guarantees.

Thus, price guarantees either have no anticompetitive effects (if hassle costs are sufficiently high and search cost are sufficiently low) or price guarantees lead to higher prices and profits for the firms and to a reduced consumer welfare. Additionally, price guarantees reduce social welfare if they lead to higher aggregate transportation costs of consumers, i.e. if firms play a mixed strategy equilibrium and if the actually chosen prices are such that one firm sets the sales price while the other firm sets the regular price.

\section{Conclusions}

In a simple spatial duopoly model with informed and uninformed consumers where firms have the option to offer price guarantees, at least one firm offers a price guarantee in all equilibria of the game. This holds even if consumers incur - in addition to travel costs search costs for gathering price information and hassle costs for using a price guarantee thereby integrating several of the models of price guarantees. Some of the results derived in the literature are reproduced in our model. So the argument that hassle costs have no impact on the competitive effects of price guarantees in the case of symmetric firms as shown by Hviid/Shaffer (1999) also follows in our model provided that consumers are perfectly informed about prices in the market and thus no search costs have to be incurred. 
Also, similar result as derived by Mao (2005) apply in our model: Competitive pricing can be an equilibrium with price guarantees if search costs are sufficiently smaller than hassle costs. If this condition is not satisfied, however, equilibria exist where firms realize higher profits. A novel feature of our model that has not yet been analysed in the literature is the use of a mixed strategy in prices that is described in the marketing literature as "high-low" pricing and that is observed in many retail businesses.

There are several points where the model presented here could be extended. First, the restrictive assumption of the symmetry of the firms could be relaxed and firms with different marginal cost, i.e. different degrees of efficiency could be considered. This would allow on the one hand to analyse - in the asymmetric equilibrium - which firm offers a price guarantee and on the other hand to examine the role of price guarantees as a signal for low prices as e.g. demonstrated under certain conditions by Moorthy/Winter (2006). The model could also be extended to allow for price beating guarantees in addition to the price meeting guarantees as considered in Hviid/Shaffer (2011). Together with asymmetric firms, this could yield further insights why some firms use price meeting guarantees while others employ price beating guarantees.

\section{References}

Arnold. T., Schwalbe, U. [2009], "Price Guarantees as a Facilitating Device - A Survey", Hohenheimer Diskussionsbeiträge 314/2009.

Arbatskaya, M. [2001], "Can Low-Price Guarantees Deter Entry", International Journal of Industrial Organization 19, 1387-1406.

Arbatskaya, M., Hvitd, M., Shaffer, G. [1999], "Promises to Match or Beat the Competition: Evidence from Retail Tire Prices", Advances in Applied Microeconomics 8, $123-138$.

Arbatskaya, M., Hvitd, M., Shaffer, G. [2004], "On the Incidence and Variety of Low-Price Guarantees", Journal of Law and Economics 47, 307-332.

Arbatskaya, M., Hvild, M., Shaffer, G. [2006], "On the Use of Low-Price Guarantees to Discourage Price-Cutting: A Test for Pairwise-Facilitation", International Journal of Industrial Organization 24, 1139-1156. 
Baye, M., Kovenock, D. [1994], "How to Sell a Pickup Truck: 'Beat-or-Pay' Advertisements as Facilitating Devices", International Journal of Industrial Organization 12, 21-33.

Belton, T. [1987], "A Model of Duopoly and Meeting or Beating Competition", International Journal of Industrial Organization 5, 399?417.

Chen, Y., Narasimhan, C., Zhang, Z.J. [2001], "Consumer Heterogeneity and Competitive Price-Matching Guarantees", Marketing Science 20, 300-314.

Corts, K. [1995], "On the Robustness of the Argument that Price-Matching is AntiCompetitive", Economics Letters 47, 417-421.

Corts, K. [1996], "On the Competitive Effects of Price-Matching Policies", International Journal of Industrial Organization 15, 283-299.

Dasgupta, P., Maskin, E. [1986], "The Existence of Equilibrium in Discontinuous Economic Games I: Theory", Review of Economic Studies 53, 1-26.

Doyle, C. [1988], "Different Selling Strategies in Bertrand Oligopoly", Economics Letters $28,387-390$.

Dugar, S. [2007], "Price-Matching Guarantees and Equilibrium Selection in a Homogenous Product Market: An Experimental Study", Review of Industrial Organization 30, 107-119.

Edlin, A. [1997], "Do Guaranteed-Low-Price Policies Guarantee High Prices, and Can Antitrust Rise to the Challenge?", Harvard Law Review 111, 528-575.

Eduin, A., Emch, E. [1999], "The Welfare Losses from Price-Matching Policies", Journal of Industrial Economics 47, 145?68

Fatá, E., Mañez, J. [2007], "Are Low-Price Compromises Collusion Guarantees? An Experimental Test of Price Matching Policies", Spanish Economic Review 9, 59-77.

Fatás, E., Georgantzãs, N., Mañez, J.A., Sabater, G. [2013], "Experimental Duopolies under Price Guarantees", Applied Economics 45, 15-35.

Hess, J., Gerstner, E. [1991], "Price Matching Policies: an Empirical Case", Managerial Decision Economics 12, 305-315.

HviID, M. [2010], "Summary of the Literature on Price-Guarantees", Working Paper, ESRC Center for competition Policy and UEA Law School.

Hvitd, M., Shaffer, G. [1999], "Hassle-Costs, The Achilles Heel of Price-Matching 
Guarantees", Journal of Economics and Management Strategy 8, 489-521.

Hvind, M.,Shaffer, G. [2010], "Matching Own Prices, Rivals' Prices, or Both", Journal of Industrial Economics 58, 479-506.

Hviıd, M.,Shaffer, G. [2011], "Optimal Low-Price Guarantees with Anchoring”, Working Paper, ESRC Center for competition Policy and UEA Law School.

Janssen, M., Parakhonyak, A. [2009], "Minimum Price Guarantees in a Consumer Search Model", Tinbergen Institute working Paper TI 2009-089/1

Kaplan, T. [2000], "Effective Price Matching: A Comment", International Journal of Industrial Organization 18, 1291-1294.

Logan, J., Lutter, R. [1989], "Guaranteed Lowest Prices: Do They Facilitate Collusion", Economics Letters 31, 189-192.

Lu, Y., Wright, J. [2010], "Tacit Collusion with Price-Matching Punishments", International Journal of Industrial Organization 28, 298-306

MaÑEz, J. [2006], "Unbeatable Value: Collusive Mechanism or Advertising Strategy?, Journal of Economics and Management Strategy 15, $143 ? 166$.

MaO, W. [2005], "Price-Matching Policy with Imperfect Information", Managerial and Decision Economics 26, 367-372.

Mago, S. D., Pate, J.G. [2009], "An Experimental Examination of Competitor-Based Price Matching Guarantees", Journal of Economic Behavior and Organization 70, 342-360. Moorthy, S., Winter, R.A. [2006], "Price-Matching Guarantees", The RAND Journal of Economics 37, 449-465.

Moorthy, S., Zhang, X. [2006] "Price Matching by Vertically Differentiated Retailers: Theory and Evidence", Journal of Marketing Research 43, 156?167.

Nalca, A., Boyaci, T., Ray, S. [2010], "Competitive Price-Matching Guarantees under Imperfect Store Availability", Quantitative Marketing and Economics 8, 275-300.

Pesendorfer [2002], "Retail Sales. A Study of Pricing Behavior in Supermarkets", Journal of Business 75, 33-66.

PNG, I.P.L., Hirshleifer, D. [1987], "Price Discrimination Through Offers to Match Price", Journal of Business 60, 365-383.

Salop, S. [1986], "Practices that (Credibly) Facilitate Oligopoly Coordination", in: Stiglitz, J., Mathewson, F. (eds.), New Developments in the Analysis of Market Struc- 
ture, MIT Press, Cambridge, MA.

Schnitzer, M. [1994], "Dynamic Duopoly with Best-Price Clauses", The RAND Journal

of Economics 25, 186-196

Winter, R. A. [2008], "Price-Matching and Meeting Competition Guarantees", in: 2

Issues in Competition Law and Policy 1269 (ABA Section of Antitrust Law).

Zhang, J. [1995], "Price-Matching Policy and the Principle of Minimum Differentiation",

Journal of Industrial Economics 43, 287-299.

\section{Appendix A}

Lemma 1 In the subgame where no firm offers a price guarantee, the unique symmetric equilibrium prices are given by $p_{i}^{*}=p^{*}=\frac{1}{2 \nu}$ and the equilibrium profits are $\pi_{i}^{*}=\frac{1}{4 \nu}$.

Proof. The prices and profits can be calculated by solving the first order conditions. To show that these prices are indeed an equilibrium, we have to check that no firm has an incentive to unilaterally deviate from the price $p^{*}$. Consider a deviation by firm 1 with a price $p_{1}>p^{*}$. For the informed consumers, this raises the cost of buying at firm 1 and thus reduces the ratio of informed consumers buying at firm 1. For uninformed consumers who visit firm 1 first, i.e. uninformed consumers with $\theta \leq 1 / 2$, an increase in the price by firm 1 triggers a search for a lower price only if the increase in price is at least as large as the search cost, i.e. if $p_{1} \geq p_{1}^{K}:=p^{*}+s$. Hence, an uninformed consumer with $\theta \leq 1 / 2$ is just indifferent between buying at firm 1 and searching and buying at firm 2 , if the following condition is satisfied

$$
\widetilde{\theta}^{N I}\left(p_{1}, p^{*}\right)=\frac{1}{2}+p^{*}-p_{1}+s
$$

To analyze whether a deviation with $p_{1} \geq p_{1}^{K}:=p^{*}+s$ is profitable for firm 1 , the profit of firm 1 evaluated at the equilibrium price $p_{2}=p^{*}$ can be stated as

$$
\pi_{1}^{D}\left(p_{1}, p^{*}\right)=\nu p_{1}\left(\frac{1}{2}+p^{*}-p_{1}\right)+(1-\nu) p_{1}\left(\frac{1}{2}+p^{*}-p_{1}+s\right)
$$

where the superscript $D$ stands for 'deviation'. Differentiating with respect to $p_{1}$ yields

$$
\frac{\partial \pi_{1}^{D}(\cdot)}{\partial p_{1}}=\frac{1}{2}+\frac{1}{2 \nu}-2 p_{1}+s(1-\nu) .
$$

Evaluating at the critical price $p_{1}^{K}=p^{*}+s$ yields

$$
\left.\frac{\partial \pi_{1}^{D}(\cdot)}{\partial p_{1}}\right|_{p_{1}=p_{1}^{K}}=-\frac{1-\nu+2 \nu(1+\nu) s}{2 \nu}<0 .
$$

As this expression is always negative, a deviation with a price $p_{1}$ that would trigger a search by the uninformed consumers given their equilibrium beliefs would not be worthwhile. An analogous argument holds for firm 2 .

A deviation with a price $p_{1}<p^{*}$ induces some of the informed consumers that bought at firm 2 at the price $p^{*}$ now to buy at firm 1, i.e. the consumers that where indifferent between the firms. With respect to the uninformed consumers, a reduction in $p_{1}$ will not change their behavior. 
The uninformed consumers with $\theta \leq 1 / 2$ will still buy at firm 1 , the uninformed consumers that visit firm 2 first will not change their behavior given the equilibrium expectations. The increase in demand by the informed consumers caused by the lower price does not outweigh the decrease in the per unit profit.

Lemma 2 In the subgame where only firm 1 offers a price guarantee a symmetric equilibrium in pure strategies with $p_{i}^{*}=p^{*}=\frac{1}{2 \nu}$ and $\pi_{i}^{*}=\frac{1}{4 \nu}$ exists as long as $s \leq s^{P}(\gamma, \nu):=\gamma /(1-\nu)$.

Proof. To show that these prices are indeed an equilibrium, we have to show that no firm has an incentive to unilaterally deviate from $p_{i}^{*}$. Note first that firm 2's deviation profits are the same as in the case without price guarantees as long as $p_{2} \geq p^{*}-\gamma$. For $p_{2} \leq p^{*}-\gamma$ firm 2's deviation profits are even lower as (informed) consumers opt for the price guarantee instead of switching to firm 2.

Turning to firm 1, consider first a deviation by firm 1 with a price $p^{*}<p_{1}<p^{*}+\gamma$. Firm 1 increases the price above the equilibrium price by an amount smaller than the hassle costs $\gamma$. As in the case without price guarantees, only prices $p_{1} \geq p_{1}^{K}:=p^{*}+s$ are relevant as otherwise the search costs are higher and an increase in $p_{1}$ would not change the behavior of the uninformed consumers buying at firm 1 . However, even if $p_{1} \geq p_{1}^{K}$, the hassle costs are larger than the possible saving and no uninformed consumer will search and claim the price guarantee. Therefore, an increase in the price by an amount smaller than the hassle costs cannot be profitable.

Second, if firm 1 deviates with a price $p_{1}$ that satisfies $p^{*}+\gamma<p_{1}$ and $p^{*}+s>p_{1}$, the informed and uninformed consumers that are indifferent whether to buy at firm 1 or firm 2 are characterized by the following conditions:

$$
\widetilde{\theta}^{I}\left(p_{1}, p^{*}\right)=\frac{1}{2}-\gamma \text { and } \widetilde{\theta}^{N I}\left(p_{1}, p^{*}\right)=\frac{1}{2}
$$

Given these demand functions, the profit of firm 1 is given by

$$
\pi_{1}^{D}\left(p_{1}, p^{*}\right)=p^{*} \nu\left(\frac{1}{2}-\gamma\right)+p_{1}(1-\nu) \frac{1}{2}
$$

Differentiation with respect to $p_{1}$ yields

$$
\frac{\partial \pi_{1}^{D}(\cdot)}{\partial p_{1}}=(1-\nu) \frac{1}{2}>0
$$

This implies that firm 1 will set the price $p_{1}^{*}=p^{*}+s=p_{1}^{K}$, i.e. the firm will increase the price up the critical level where an uninformed consumer would begin to search for a lower price. Evaluating the profit of firm 1 at this price gives

$$
\left.\pi_{1}^{D}\right|_{p_{1}=p_{1}^{K}}=\frac{1}{4 \nu}[1-2 \nu(\gamma-(1-\nu) s)]
$$

Therefore, a deviation is not profitable as long as

$$
\gamma-(1-\nu) s \geq 0 \Leftrightarrow s \leq \frac{\gamma}{1-\nu}
$$

We also have to consider the case where firm 1 deviates from $p^{*}$ by charging a price $p_{1}$ that satisfies $p^{*}+\max \{\gamma, s\}<p_{1}$, i.e. firm 1 deviates with a price $p_{1}$ that makes a search as well as using the price guarantee worthwhile. For the informed consumers, the demand is again given by

$$
\widetilde{\theta}^{I}\left(p_{1}, p^{*}\right)=\frac{1}{2}-\gamma
$$


For the uninformed consumers, two cases have to be considered. First, the uninformed consumers who searches for a lower price and switches to the other firm but do not use the price guarantee. Second, the uninformed consumers who search for a lower price and use the price guarantee instead of buying from the other firm. However, the total costs for search and using the price guarantee are given by $s+\gamma>s$. Hence, we can focus on a deviation with $p^{*}+s+\gamma>p_{1}>p^{*}+s$. Then, demand of uninformed consumers is given by

$$
\widetilde{\theta}^{N I}\left(p^{*}, p_{1}\right)=\frac{1}{2}+p_{1}-\left(p^{*}+s\right)
$$

The profit of firm 1 can be written as

$$
\pi_{1}^{D}\left(p_{1}, \cdot\right)=\nu p^{*} \widetilde{\theta}^{I}+(1-\nu) p^{*} \widetilde{\theta}^{N I}
$$

As

$$
\left.\frac{\partial \pi_{1}^{D}\left(p_{1}, \cdot\right)}{\partial p_{1}}\right|_{p_{1}=p^{*}+s}=(1-\nu) \frac{1-\nu(1-2 s)}{2 \nu}<0
$$

an increase of $p_{1}$ above $p^{*}+s$ can not be profitable. As $p_{1}>p^{*}+s+\gamma$ would induce consumers to use the price guarantee such a deviation can not be profitable either.

Finally, considering deviations with a lower price, a similar argument as in the case without price guarantees applies. Some additional informed consumers are attracted but the increase in demand is more than offset by the decrease in per-unit profits. The uninformed consumers-given their equilibrium beliefs - will not change their behavior.

Lemma 3 In the subgame where only firm 1 offers a price guarantee and $s>s^{P}(\gamma, \nu):=\gamma /(1-\nu)$, a mixed strategy equilibrium exists and is characterized by

$$
\begin{aligned}
& \bar{p}_{1}=p_{2}+s \\
& \underline{p}_{1}=\frac{2\left(1-\rho_{1}\right)+\nu\left(1+2 \rho_{1}\left(\gamma\left(1-(1-\nu) \rho_{1}\right)-\left(1-\nu-2 \rho_{1}(1-\nu)\right) s\right)\right)}{2 \nu\left(1-\rho_{1}\right)\left(2+\nu-(1-\nu) \rho_{1}\right)} \\
& p_{2}-\underline{p}_{1}=\frac{\rho_{1}\left(1+2 \gamma \nu+2(1-\nu)\left(2-\rho_{1} s\right)\right.}{2 \nu\left(1-\rho_{1}\right)\left(2+\nu-(1-\nu) \rho_{1}\right)}>0
\end{aligned}
$$

and $\rho_{1}$ such that $\pi_{1}\left(\bar{p}_{1}, \cdot\right)=\pi_{1}\left(\underline{p}_{1}, \cdot\right)$.

Proof. We start with $\underline{p}_{1}$ and $p_{2}$. Using (15) and (16) and $\bar{p}_{1}=p_{2}+s$ we obtain

$$
\begin{gathered}
\frac{\partial \pi_{1}\left(\underline{p}_{1}, \cdot\right)}{\partial \underline{p}_{1}}=\frac{1}{2}+p_{2}-\underline{p}_{1}\left(1+\nu-(1-\nu) \rho_{1}\right)-(1-\nu) \rho_{1}\left(p_{2}+s\right) \\
\frac{\partial E \pi_{2}\left(p_{2}, \cdot\right)}{\partial p_{2}}=\frac{1}{2}+\underline{p}_{1}-(1+\nu) p_{2}\left(1-\rho_{1}\right)-\rho_{1} \underline{p}_{1}+\rho_{1}(\nu \gamma+s(1-\nu))
\end{gathered}
$$

Solving these equations leads to the prices $\underline{p}_{1}$ and $p_{2}$ given the lemma. Defining $\mu:=\frac{1-\nu}{\gamma} s>1$ due to $s>s^{P}(\gamma, \nu)$ we also get

$$
\begin{aligned}
\frac{\partial \pi_{1}\left(\bar{p}_{1}, \cdot\right)}{\partial \bar{p}_{1}} & =\frac{(1-\nu)\left(2+\nu\left(1+\rho_{1}(1+2 \gamma)\right)\right)+6 \gamma \rho_{1} \mu}{2\left(2+\nu-(1-\nu) \rho_{1}\right)} \\
p_{2}-\underline{p}_{1} & =\frac{\rho_{1}\left(1+2 \gamma \nu+2 \gamma\left(2-\rho_{1}\right) \mu\right)}{2\left(1-\rho_{1}\right)\left(2+\nu-(1-\nu) \rho_{1}\right)} .
\end{aligned}
$$


Turning to $\pi_{1}\left(\bar{p}_{1}, \cdot\right)=\pi_{1}\left(\underline{p}_{1}, \cdot\right)$ substituting $\bar{p}_{1}, \underline{p}_{1}$ and $p_{2}$ shows

$$
\begin{aligned}
& \lim _{\rho_{1} \rightarrow 0}\left[\pi_{1}\left(\bar{p}_{1}, \cdot\right)-\pi_{1}\left(\underline{p}_{1}, \cdot\right)\right]=-\gamma(1-\mu)>0 \text { and } \\
& \lim _{\rho_{1} \rightarrow 1}\left[\pi_{1}\left(\bar{p}_{1}, \cdot\right)-\pi_{1}\left(\underline{p}_{1}, \cdot\right)\right]<0 .
\end{aligned}
$$

Hence, there always exist a $\rho_{1}$ such that firm 1 is indifferent between charging the high and the low price, respectively. Furthermore, (52) and (53) reveal $\partial \pi_{1}\left(\bar{p}_{1}, \cdot\right) / \partial \bar{p}_{1} \geq 0$ and $p_{2}-\underline{p}_{1} \geq 0$.

Finally, we have to check whether profitable deviations exist such that uninformed would search. Consider first firm 1. Any deviation by firm 1 such that uninformed consumers who visited firm 1 first would search can not profitable. Choosing $p_{1}>p_{2}+s$ implies that demand of uninformed consumers is given by with

$$
\widetilde{\theta}^{N I}\left(p^{*}, p_{1}\right)=\frac{1}{2}+p_{1}-\left(p_{2}+s\right) .
$$

Using the profit of firm 1

$$
\pi_{1}^{D}\left(p_{1}, \cdot\right)=\nu p_{2} \widetilde{\theta}^{I}+(1-\nu) p_{2} \widetilde{\theta}^{N I}
$$

and evaluating the first derivative with respect to $p_{1}$, shows

$$
\left.\frac{\partial \pi_{1}^{D}\left(p_{1}, \cdot\right)}{\partial p_{1}}\right|_{p_{1}=p_{2}+s}<0
$$

Similar reasoning applies to firm 2 . An increase of $p_{2}$ above the level at which uninformed consumers visiting firm 2 first start to search can not be profitable: $p_{2}$ is optimal given no search and search implies that some uninformed consumers may switch to firm 1.

Corollary 1 A mixed strategy equilibrium yields higher profits for the firm which uses price guarantees, i.e.

$$
E \pi_{1}^{*}>\pi^{*}
$$

Proof. Using the equilibrium prices given in lemma (3) and $E \pi_{1}^{*}=\pi_{1}\left(\underline{p}_{1}, \cdot\right)$ we obtain

$$
\begin{aligned}
\frac{\pi_{1}\left(\underline{p}_{1}, \cdot\right)}{\pi_{i}^{*}} & =\frac{\left(2-2 \rho_{1}+\nu\left(1+2 \rho_{1}\left(\gamma+\gamma(-1+\nu) \rho_{1}\left(-1+\nu+2 \rho_{1}-2 \nu \rho_{1}\right) s\right)\right)\right)^{2}}{\left(-1+\rho_{1}\right)^{2}\left(2+\nu-(1-\nu) \rho_{1}\right)^{2}}>1 \\
& \Leftrightarrow(1+2 \gamma \nu) \rho_{1}\left(1+(-1+\nu) \rho_{1}\right)-2(-1+\nu) \nu \rho_{1}\left(-1+2 \rho_{1}\right) s>0 \\
& \Leftrightarrow \rho_{1}\left(1+(-1+\nu) \rho_{1}-2(-1+\nu) \nu\left(-1+2 \rho_{1}\right) s\right)>0
\end{aligned}
$$

where the last inference follows from

$$
\frac{d}{d \gamma}\left((1+2 \gamma \nu) \rho_{1}\left(1+(-1+\nu) \rho_{1}\right)-2(-1+\nu) \nu \rho_{1}\left(-1+2 \rho_{1}\right) s\right)=2 \nu \rho_{1}\left(1+(-1+\nu) \rho_{1}\right)>0
$$

Analyzing the sign of $1+(-1+\nu) \rho_{1}-2(-1+\nu) \nu\left(-1+2 \rho_{1}\right) s$ and using

$$
\frac{d^{2}}{d \rho_{1}^{2}}\left[1+(-1+\nu) \rho_{1}-2(-1+\nu) \nu\left(-1+2 \rho_{1}\right) s\right]=0
$$


as well as

$$
\begin{aligned}
& 1+(-1+\nu) \rho_{1}-\left.2(-1+\nu) \nu\left(-1+2 \rho_{1}\right) s\right|_{\rho_{1}=0}=1-2(1-\nu) \nu s \geq 0 \forall s \leq 2 \\
& 1+(-1+\nu) \rho_{1}-\left.2(-1+\nu) \nu\left(-1+2 \rho_{1}\right) s\right|_{\rho_{1}=1}=\nu+2(1-\nu) \nu s \geq 0
\end{aligned}
$$

we get

$$
\forall \rho_{1} \in[0,1]: 1+(-1+\nu) \rho_{1}-2(-1+\nu) \nu\left(-1+2 \rho_{1}\right) s>0
$$

Lemma 4 In the subgame where both firms offer price guarantees and use pure strategies with respect to prices, the prices and profits in a symmetric equilibrium are given by $p_{i}^{* *}=p^{*}=\frac{1}{2 \nu}$ and $\pi_{i}^{* *}=\pi_{i}^{*}=\frac{1}{4 \nu}$ provided that $s \leq s^{P}(\gamma, \nu)$.

Proof. The proof is analogous to the proof of lemma 2.

Lemma 5 There exists a unique probability $\rho^{*}(\nu, \gamma) \in(0,1)$ such that $E \pi_{i}(\underline{p}, \cdot)=E \pi_{i}(\bar{p}, \cdot)$ holds.

Proof. We start by defining

$$
\begin{aligned}
\Delta E \pi & :=E \pi_{i}(\underline{p}, \cdot)-E \pi_{i}(\bar{p}, \cdot) \\
& =\frac{2 \rho-1+\nu(2-\rho(5-3 \rho-2 \gamma(1+\rho))-\nu(1-\rho-2 \gamma \rho)(1-\rho(2-2 \gamma-\rho)))}{4 \nu(1-\rho) \rho}
\end{aligned}
$$

Solving $\Delta E \pi=0$ for $\gamma$ we get that there exist two solutions $\gamma_{1}(\nu, \rho)<0<\gamma_{2}(\nu, \rho)$ with

$$
\gamma_{2}(\nu, \rho)=\frac{1}{4 \nu^{2} \rho^{2}}\left[\begin{array}{c}
\nu \rho \sqrt{(1-\rho)\left(5-\nu\left(2(4-\rho)-\nu(2-\rho)^{2}\right)(1-\rho)-\rho\right)} \\
-\nu \rho(1+(1-\nu(1-\rho)) \rho)
\end{array}\right]
$$

Analyzing $\gamma_{2}(\nu, \rho)$ with respect to $\rho$ shows that

$$
\lim _{\rho \rightarrow 0} \gamma_{2}(\nu, \rho)=\infty ; \lim _{\rho \rightarrow 1} \gamma_{2}(\nu, \rho)=-\frac{1}{2 \nu}<0 \text { and } \operatorname{sign} \frac{\partial \gamma_{2}(\nu, \rho)}{\partial \rho}<0 \forall \nu, \rho \in(0,1)
$$

Thus, for any given $\gamma \geq 0$ there exist a unique $\rho^{*}(\nu, \gamma) \in(0,1)$ such that $\gamma_{2}(\nu, \rho)=\gamma$ and thus $\Delta E \pi=0$.

Lemma 6 In the subgame where both firms use price guarantees, there exists an equilibrium in mixed strategies provided that the search costs $s$ is higher than a critical level $s^{M}(\gamma, \nu)$ given by

$$
s^{M}(\gamma, \nu):=\frac{1-2 \rho^{*}(\nu, \gamma)-\nu\left(1-\rho^{*}(\nu, \gamma)\left(2-\rho^{*}(\nu, \gamma)-2 \gamma \rho^{*}(\nu, \gamma)\right)\right)}{2 \nu v \rho^{*}(\nu, \gamma)}
$$

The prices between the firms mix are given by

$$
\underline{p}(\gamma, \nu)=\frac{1+2 \gamma \nu \rho^{*}(\nu, \gamma)}{2 \nu\left(1-\rho^{*}(\nu, \gamma)\right)} \quad \text { and } \quad \bar{p}(\gamma, \nu)=\frac{1-\nu\left(1-\rho^{*}(\nu, \gamma)\right)}{2 \nu \rho^{*}(\nu, \gamma)}
$$


Proof. Using (29) and (30), the condition that price guarantees are used, i.e. $\bar{p}-\underline{p}>\gamma$ can be written as

$$
\bar{p}-(\underline{p}+\gamma)=\frac{1-2 \rho^{*}-\nu\left(1-\rho^{*}\left(2-2 \gamma-\rho^{*}\right)\right)}{2 \nu \rho^{*}\left(1-\rho^{*}\right)}>0 .
$$

To show that (70) is satisfied, we substitute $\gamma_{2}(\nu, \rho)$ defined in $(68)$ instead of $\rho^{*}(\nu, \gamma)$ which leads to

$$
\begin{aligned}
\bar{p}-\left(\underline{p}+\gamma_{2}(\nu, \rho)\right) & \geq 0 \Leftrightarrow \\
\nu(3-\nu(2-\rho))(1-\rho) \rho & \geq \nu \rho \sqrt{(1-\rho)\left(5-\nu\left(2(4-\rho)-\nu(2-\rho)^{2}\right)(1-\rho)-\rho\right)}
\end{aligned}
$$

While inequality $(72)$ does not hold for all $\rho \in(0,1)$, (68) also implies that there exist an upper bound for the equilibrium values of $\rho$, i.e.

$$
\gamma=\gamma_{2}(\nu, \rho)>0 \Rightarrow \rho^{*}(\nu, \gamma)<\frac{\nu+\sqrt{1-\nu}-1}{\nu}
$$

Tedious calculations show that $\bar{p}-(\underline{p}+\gamma)>0$ holds for all $\rho \in\left(0, \frac{\nu+\sqrt{1-\nu}-1}{\nu}\right)$.

In addition, the critical level of the search $\operatorname{costs} s^{M}$ such that uninformed consumers will not search is determined by

$$
\bar{p}+\frac{1}{2} \theta^{2} \leq \rho^{*}\left(\bar{p}+\frac{1}{2} \theta^{2}\right)+\left(1-\rho^{*}\right)\left(\underline{p}+\frac{1}{2}(1-\theta)^{2}\right)+s
$$

This is equivalent to (using $\theta=1 / 2$ )

$$
s \geq \frac{1-2 \rho^{*}-\nu\left(1-\rho^{*}\left(2-\rho^{*}-2 \gamma \rho^{*}\right)\right)}{2 \nu \rho^{*}} .
$$

To show that mixing between $\bar{p}$ and $p$ is indeed an equilibrium, we have to consider possible deviations from the mixed strategy, i.e. the choice of a uniform price. As in the proof of lemma 2, different types of deviations have to be considered.

First, suppose that $\underline{p}+\gamma<\bar{p}-\gamma$ and consider a deviation with a uniform price $p_{1}$ that satisfies $\underline{p}+\gamma<p_{1}<\bar{p}-\gamma$. Then, demand for firm 1 by informed consumers is determined by the consumer that is indifferent between buying at firm 1 or firm 2 .

$$
\widetilde{\theta}^{I}\left(p_{1}, \underline{p}\right)=\frac{1}{2}-\gamma \quad \text { and } \quad \widetilde{\theta}^{I}\left(p_{1}, \bar{p}\right)=\frac{1}{2}+\gamma
$$

As $p_{1}<\bar{p}$, uninformed consumers have no incentive to search. Accordingly, the expected profit $E \pi_{1}^{D}\left(p_{1}, \cdot\right)$ from a deviating with $\underline{p}+\gamma<p_{1}<\bar{p}-\gamma$ can be written as

$$
\begin{aligned}
E \pi_{1}^{D}\left(p_{1}, \cdot\right) & =\nu\left(\rho^{*} p_{1} \widetilde{\theta}^{I}\left(p_{1}, \bar{p}\right)+\left(1-\rho^{*}\right) \underline{p} \widetilde{\theta}^{I}\left(p_{1}, \underline{p}\right)\right)+(1-\nu) p_{1} \frac{1}{2} \\
& =\frac{1}{4}\left(1-2 \gamma+2 p_{1}-2 \nu p_{1}+2 \nu\left(\gamma-2 \gamma^{2}+p_{1}+2 \gamma p_{1}\right) \rho^{*}\right) .
\end{aligned}
$$

Differentiating this profit with respect to $p_{1}$ yields

$$
\frac{\partial E \pi_{1}^{D}\left(p_{1}, \cdot\right)}{\partial p_{1}}=\frac{1}{2}\left(1-\nu\left(1-r-2 \gamma \rho^{*}\right)\right)>0 .
$$


Thus, the firm will set the price $p_{1}$ at the level $p_{1}=\bar{p}-\gamma$. The difference between the profit from a deviation given that value of $p_{1}$ and the profit using the mixed strategy is given by

$$
\begin{aligned}
& E \pi_{1}^{D}-E \pi_{1}= \\
& \frac{1-2 \rho^{*}-\nu\left(2-\rho^{*}\left(5-3 \rho^{*}-2 \gamma\left(1+\rho^{*}\right)\right)-\nu\left(1-\rho^{*}\left(3-(1+2 \gamma) \rho^{*}\left(3-4 \gamma-\rho^{*}\right)\right)\right)\right)}{4 \nu \rho^{*}} .
\end{aligned}
$$

Again, substituting $\gamma_{2}(\nu, \rho)$ instead of $\rho^{*}$ and taking into account $\rho^{*}(\nu, \gamma)<\frac{\nu+\sqrt{1-\nu}-1}{\nu}$, tedious calculations show that $E \pi_{1}^{D}-E \pi_{1}<0$ holds for all $\rho<\frac{\nu+\sqrt{1-\nu}-1}{\nu}$ and $\nu \in(0,1)$.

Secondly, we consider a deviation with $\bar{p}<p_{1}<\bar{p}+\gamma$. Notice that only prices $p_{1}$ are relevant that satisfy the condition $p_{1} \geq p_{1}^{K}:=\rho^{*} \bar{p}+\left(1-\rho^{*}\right) \underline{p}+s$, i.e. searching for a lower price is worthwhile for consumer $\theta=1 / 2$.

The uninformed consumer that is just indifferent between searching for a lower price and switching to firm 2 and not searching is determined by the condition

$$
\widetilde{\theta}^{N I}\left(p_{1}\right)=\frac{1}{2}+\rho^{*} \bar{p}+\left(1-\rho^{*}\right) \underline{p}-p_{1}+s
$$

The informed consumer that is indifferent between buying at firm 1 or firm 2 is again characterized by

$$
\widetilde{\theta}^{I}\left(p_{1}, \underline{p}\right)=\frac{1}{2}-\gamma \quad \text { and } \quad \tilde{\theta}^{I}\left(p_{1}, \bar{p}\right)=\frac{1}{2}+\gamma .
$$

Given the demand of the informed and uninformed consumers, the expected profit of firm 1 can be written as

$$
E \pi_{1}^{D}\left(p_{1}, \cdot\right)=p_{1}\left[\nu\left(\rho^{*} \widetilde{\theta}^{I}\left(p_{1}, \bar{p}\right)+\left(1-\rho^{*}\right) \widetilde{\theta}^{I}\left(p_{1}, \underline{p}\right)\right)+(1-\nu) \widetilde{\theta}^{N I}\left(p_{1}\right)\right] .
$$

To examine whether a deviation is profitable, we differentiate firm 1's expected profit with respect to $p_{1}$ which yields

$$
\frac{\partial E \pi_{1}^{D}\left(p_{1}, \cdot\right)}{\partial p_{1}}=(-1+\nu) p_{1}+\frac{1}{2} \nu\left(1-4 p_{1}+2 \bar{p}\right) \rho^{*}+(1-\nu)\left(\frac{1}{2}-p_{1}+\rho^{*} \bar{p}+\left(1-\rho^{*}\right) \underline{p}+s\right)
$$

Inserting the equilibrium values for $\bar{p}$ and $\underline{p}$, evaluating the derivative of $\partial E \pi_{1}^{D} / \partial p_{1}$ at $p_{1}=p_{1}^{K}$ yields

$$
\left.\left(\frac{\partial E \pi_{1}\left(p_{1}, \cdot\right)}{\partial p_{1}}-\frac{\partial E \pi_{1}^{D}\left(p_{1}, \cdot\right)}{\partial p_{1}}\right)\right|_{p_{1}=p_{1}^{K}}=\frac{(1-\nu)\left(2-\nu\left(1-\rho^{*}-2 \gamma \rho^{*}-2 s\right)\right)}{2 \nu}>0
$$

As $p_{1}^{K}>\bar{p}$, it follows that

$$
\left.\frac{\partial E \pi_{1}\left(\bar{p}_{1}, \cdot\right)}{\partial \bar{p}_{1}}\right|_{p_{1}=p_{1}^{K}}<\left.0 \Rightarrow \frac{\partial E \pi_{1}^{D}\left(p_{1}, \cdot\right)}{\partial p_{1}}\right|_{p_{1}=p_{1}^{K}}<0 .
$$

(84) together with

$$
\frac{\partial^{2} E \pi_{1}^{D}\left(p_{1}, \cdot\right)}{\partial p_{1}^{2}}=-2+2 \nu\left(1-\rho^{*}\right)<0
$$

show that a deviation from the mixed strategy by choosing a uniform price $p_{1}$ with $\bar{p}<p_{1}<\bar{p}+\gamma$ such that part of the consumers search is not profitable. The same reasoning holds for even higher 
prices $p_{1}>\bar{p}+\gamma$.

Corollary 2 If both firms use price guarantees, the firms' expected profits $E \pi_{i}^{* *}=E \pi^{* *}$ in a mixed strategy equilibrium are given by

$$
E \pi^{* *}(\cdot)=\frac{\left(1+2 \gamma \nu \rho^{*}(\nu, \gamma)\right)^{2}}{4 \nu\left(1-\rho^{*}(\nu, \gamma)\right)}>\frac{1}{4 \nu}=\pi^{*}
$$

Furthermore, comparative statics with respect to $\gamma$ shows that $E \pi^{* *}(\cdot)$ increases in $\gamma$ as long as $\gamma$ and $\nu$ are small enough.

Proof. The first part of the corollary follows from the equilibrium prices given in lemma 6. Furthermore, using lemma 5 and assuming $\gamma=0$ we obtain

$$
\left.\rho^{*}(\nu, 0)\right|_{\gamma=0}=\frac{\nu-1+\sqrt{1-n}}{\nu}<0 \text { and }\left.\frac{\partial \rho^{*}(\nu, \gamma)}{\partial \gamma}\right|_{\gamma=0}=-1+\frac{2-2 \sqrt{1-n}}{\nu}-\frac{\nu}{\sqrt{1-\nu}} \text {. }
$$

Using these expressions and differentiating $E \pi_{i}(\underline{p}, \cdot)$ with respect to $\gamma$ we get

$$
\left.\frac{\partial E \pi_{i}(\underline{p}, \cdot)}{\partial \gamma}\right|_{\gamma=0}=\frac{1}{4}\left(3 \sqrt{1-n}-1-\frac{1}{\sqrt{1-\nu}}\right)
$$

and therefore $\partial E \pi_{i}(\underline{p}, \cdot) /\left.\partial \gamma\right|_{\gamma=0}>0$ for all $\nu<0.41$.

Result 1 For all $s \geq s^{P}(\gamma, \nu)$, the best reply of firm 2 to $P G$ by firm 1 is to choose PG, i.e. $E \pi_{1}^{*}>E \pi_{2}^{*}$.

Proof. The following proof is based on numerical simulations. To incorporate the restrictions

$$
s \geq s^{P}(\gamma, \nu) \text { and } s, \gamma \in[0,0.5]
$$

we define the following two variables

$$
\widetilde{s}(\nu, \gamma, \lambda)=\lambda s^{P}(\gamma, \nu)+(1-\lambda) \frac{1}{2} \text { and } \widetilde{\gamma}(\nu, \kappa)=\kappa \frac{1}{2}(1-\nu)
$$

Considering $\lambda, \kappa \in[0,1]$ and substituting $\widetilde{s}$ and $\widetilde{\gamma}$ for $s$ and $\gamma$ in the firms' profit functions, we can analyze the difference $E \pi_{1}^{*}-E \pi_{2}^{*}$ for all parameter constellations for which a mixed strategy equilibrium exists if only firm 1 offers price guarantees.

Using lemma 3 and 6 , solving $\pi_{1}\left(\bar{p}_{1}, \cdot\right)=\pi_{1}\left(\underline{p}_{1}, \cdot\right)$ for $\rho_{1}$ as well as $E \pi_{i}(\underline{p}, \cdot)=E \pi_{i}(\bar{p}, \cdot)$ for $\rho^{*}$, the following figure shows the graph of $E \pi_{1}^{*}-E \pi_{2}^{*}$ as a function of $\lambda$ and $\kappa$ for $\nu=0.2$ and $\nu=0.8$. Considering different values of $\nu$, we find that $E \pi_{1}^{*}-E \pi_{2}^{*}$ is positive for all $\nu, \lambda, \kappa \in[0,1]$ and we get

$$
\lim _{\nu \rightarrow 1} E \pi_{1}^{*}-\left.E \pi_{2}^{*}\right|_{\lambda=k=0}=0 .
$$

Hence, we can conclude that $E \pi_{1}^{*}>E \pi_{2}^{*}$ holds for all $s \geq s^{P}(\gamma, \nu)$ and $s, \gamma \in[0,0.5]$. 

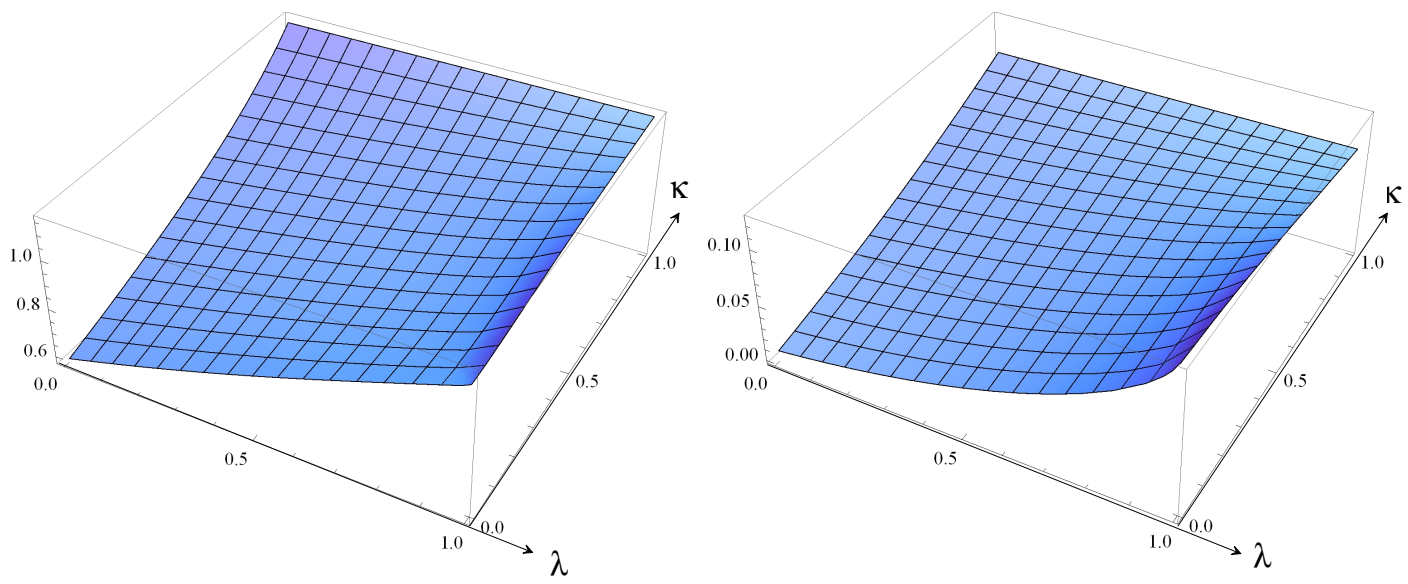

Figure 3: $E \pi_{1}^{*}-E \pi_{2}^{*}$ for $\nu=0.2$ (left) and $\nu=0.8$ (right).

\section{Appendix B}

\section{Non-existence of mixed strategy equilibria without price guarantees}

In order to show that without price guarantees there are no equilibria in mixed strategies we focus on mixed strategies where firms use only two prices.

Assume first that both firms randomly choose either a low price $\underline{p}_{i}$ or a high price $\bar{p}_{i}>\underline{p}_{i}$ and assume that observing $\bar{p}_{i}$ does not induce uninformed consumers to search. Let $\bar{p}_{i}^{e}$ and $\underline{p}_{i}^{e} \overline{\text { denote }}$ the expected high and low price of firm $i$ and let $\rho_{i}$ be the probability that firm $i$ chooses $\bar{p}_{i}^{e}$. Then, the indifferent informed and uninformed consumers are given $\left(p_{i}\right.$ refers to the actually chosen price of firm $i$ )

$$
\begin{aligned}
\theta^{I}(\cdot) & =\frac{1}{2}+p_{1}-p_{2} . \\
\theta^{N I}(\cdot) & =\frac{1}{2}+\left[\rho_{2} \bar{p}_{2}^{e}+\left(1-\rho_{2}\right) \underline{p}_{2}^{e}\right]-\left[\rho_{1} \bar{p}_{1}^{e}+\left(1-\rho_{1}\right) \underline{p}_{1}^{e}\right]
\end{aligned}
$$

Turning to the firms profits and focusing on firm 1, we obtain

$$
\begin{aligned}
& \pi_{1}^{e}\left(\bar{p}_{1}\right)=\nu \bar{p}_{1}\left[\rho_{2} \theta^{I}\left(\bar{p}_{1}, \bar{p}_{2}\right)+\left(1-\rho_{2}\right) \theta^{I}\left(\bar{p}_{1}, \underline{p}_{2}\right)\right]+(1-\nu) \theta^{N I}\left(\bar{p}_{1}^{e}, \underline{p}_{1}^{e}, \bar{p}_{2}^{e}, \underline{p}_{2}^{e}\right) \\
& \pi_{1}^{e}\left(\underline{p}_{1}\right)=\nu \underline{p}_{1}\left[\rho_{2} \theta^{I}\left(\underline{p}_{1}, \bar{p}_{2}\right)+\left(1-\rho_{2}\right) \theta^{I}\left(\underline{p}_{1}, \underline{p}_{2}\right)\right]+(1-\nu) \theta^{N I}\left(\bar{p}_{1}^{e}, \underline{p}_{1}^{e}, \bar{p}_{2}^{e}, \underline{p}_{2}^{e}\right)
\end{aligned}
$$

Using the respective expression for firm 2, solving the first order conditions for the optimal prices $\bar{p}_{i}^{*}$ and $\underline{p}_{i}^{*}$ and using fulfilled expectations, i.e. $\bar{p}_{i}^{e}=\bar{p}_{i}^{*}$ and $\underline{p}_{i}^{e}=\underline{p}_{i}^{*}$, we obtain

$$
\bar{p}_{i}^{*}=\underline{p}_{i}^{*}=\frac{1}{2 \nu}
$$

which contradicts $\bar{p}_{i}>\underline{p}_{i}$.

Again, assume that $\bar{p}_{i}>\underline{p}_{i}$ but that observing $\bar{p}_{i}$ induces (some) uninformed consumers to search. Assume that an uninformed consumer goes first to firm $i$, searches if firm $i$ sets the higher price $\bar{p}_{i}$ and buys from firm $j$ if he observes $\bar{p}_{j}$. Then, the expected expenditures $c_{1}^{E S}$ and $c_{2}^{E S}$ for going 
first to firm 1 or 2 , respectively, are given by

$$
\begin{aligned}
& E\left[c_{1}^{E S}\right]=\rho_{1}\left[\rho_{2}\left(\bar{p}_{1}^{e}+\frac{1}{2} \theta^{2}\right)+\left(1-\rho_{2}\right)\left(\underline{p}_{2}^{e}+\frac{1}{2}(1-\theta)^{2}\right)+s\right]+\left(1-\rho_{1}\right)\left[\underline{p}_{1}^{e}+\frac{1}{2} \theta^{2}\right] \\
& E\left[c_{2}^{E S}\right]=\rho_{2}\left[\rho_{1}\left(\bar{p}_{2}^{e}+\frac{1}{2}(1-\theta)^{2}\right)+\left(1-\rho_{1}\right)\left(\underline{p}_{1}^{e}+\frac{1}{2} \theta^{2}\right)+s\right]+\left(1-\rho_{2}\right)\left[\underline{p}_{2}^{e}+\frac{1}{2}(1-\theta)^{2}\right]
\end{aligned}
$$

Solving $E\left[c_{1}^{E S}\right]=E\left[c_{2}^{E S}\right]$ for $\theta$ leads to the consumer $\theta^{N I}(\cdot)$ who is indifferent between going first to firm 1 or 2. To calculate the firms' expected profits we also need to determine the consumer whogiven the actual firms' prices - is indifferent between searching (and switching) and not searching. Focusing on the price combinations which lead to a switch of consumers, the consumers $\widetilde{\theta}_{1}^{N I S}\left(\bar{p}_{1}, \cdot\right)$ and $\widetilde{\theta}_{2}^{N I S}\left(\bar{p}_{2}, \cdot\right)$ who are indifferent between searching (and switching) are implicitly given by

$$
\begin{aligned}
& \widetilde{\theta}_{1}^{N I S}\left(\bar{p}_{1}, \cdot\right): \bar{p}_{1}+\frac{1}{2} \theta^{2}=\rho_{2}\left(\bar{p}_{2}^{e}+\frac{1}{2} \theta^{2}\right)+\left(1-\rho_{2}\right)\left(\underline{p}_{2}^{e}+\frac{1}{2}(1-\theta)^{2}\right)+s \\
& \widetilde{\theta}_{2}^{N I S}\left(\bar{p}_{2}, \cdot\right): \bar{p}_{2}+\frac{1}{2}(1-\theta)^{2}=\rho_{1}\left(\bar{p}_{2}^{e}+\frac{1}{2}(1-\theta)^{2}\right)+\left(1-\rho_{1}\right)\left(\underline{p}_{1}^{e}+\frac{1}{2} \theta^{2}\right)+s .
\end{aligned}
$$

Accordingly, firm 1's expected profits can be written as

$$
\begin{aligned}
& \pi_{1}^{e}\left(\bar{p}_{1}\right)=\bar{p}_{1}\left[\rho_{2} \theta^{I}\left(\bar{p}_{1}, \bar{p}_{2}\right)+\left(1-\rho_{2}\right)\left(\nu \theta^{I}\left(\bar{p}_{1}, \underline{p}_{2}\right)+(1-\nu) \widetilde{\theta}_{1}^{N I S}\left(\bar{p}_{1}^{e}, \cdot\right)\right)\right] \\
& \pi_{1}^{e}\left(\underline{p}_{1}\right)=\underline{p}_{1}\left[\rho_{2}\left(\nu \theta^{I}\left(\underline{p}_{1}, \bar{p}_{2}\right)+(1-\nu) \widetilde{\theta}_{2}^{N I S}\left(\bar{p}_{2}^{e}, \cdot\right)\right)+\left(1-\rho_{2}\right)\left(\nu \theta^{I}\left(\underline{p}_{1}, \underline{p}_{2}\right)+(1-\nu) \theta^{N I}(\cdot)\right)\right] .
\end{aligned}
$$

Note that with $\bar{p}_{1}$ and $\bar{p}_{2}$ the indifferent uninformed consumer searches and therefore behaves as the informed consumers. Using the respective expression for firm 2, restricting the analysis to symmetry, i.e. $\rho=\rho_{1}=\rho_{2}$, and solving the first order conditions for the optimal prices $\bar{p}_{i}^{*}$ and $\underline{p}_{i}^{*}$ we get (again using fulfilled expectations)

$$
\begin{aligned}
\bar{p}_{i}^{*} & =\frac{1+\nu+2(1-\nu) \nu s}{2 \nu(2-\rho)+2 \rho} \\
\underline{p}_{i}^{*} & =\frac{1-\rho(1+(1-\nu) s)}{(1-\rho)(\rho+n(2-\rho)} .
\end{aligned}
$$

Substituting these prices in $\widetilde{\theta}_{2}^{N I S}\left(\bar{p}_{2}^{*}, \cdot\right)$ leads to

$$
\widetilde{\theta}_{2}^{N I S}\left(\bar{p}_{2}^{*}, \cdot\right)-\frac{1}{2}=-\frac{1-\rho-\nu(1-2(1+\nu) s-\rho(1+2(1-\nu) s))}{2(1-\rho)(\rho+2 \nu(2-\rho)}<0 \text { for all } \nu, \rho \in[0,1]^{2} .
$$

But since $\widetilde{\theta}_{2}^{N I S}\left(\bar{p}_{2}^{*}, \cdot\right) \leq 1 / 2$ violates the assumption that at least some uninformed consumers would search if they observed a high price, the proposed equilibrium does not exist.

\section{Non-existence of mixed strategy equilibria with search and price guarantees}

In order to show that with price guarantees a mixed strategy equilibrium where some uninformed consumers may search does not exist, we start by characterizing the conditions that have to be satisfied in such an equilibrium. We then show that these conditions lead to a contradiction with respect to the assumed pricing structure. We again focus on symmetric equilibria where firms randomly choose among two prices only.

As in the case without search of uninformed consumers, the behavior of informed consumers can 
be characterized by (see (23))

$$
\theta^{I}(\cdot)=\left\{\begin{array}{lll}
\frac{1}{2}+\gamma & \text { if } & p_{1}=\underline{p}_{1}<p_{2}=\bar{p}_{2} \\
\frac{1}{2}-\gamma & \text { if } & p_{1}=\bar{p}_{1}>p_{2}=\underline{p}_{2} \\
\frac{1}{2}+p_{2}-p_{1} & \text { otherwise } &
\end{array}\right.
$$

Considering uninformed consumers, the expected expenditures for going first to firm 1 or 2, respectively, are given by $\left(E\left[c_{i}^{E S}\right]\right.$ and $E\left[c_{i}^{E G}\right]$ denote the expected costs for searching and switching and searching and using the price guarantee, respectively)

$$
\begin{aligned}
E\left[c_{1}^{E S}\right] & =\rho_{1}\left[\rho_{2}\left(\bar{p}_{1}^{e}+\frac{1}{2} \theta^{2}\right)+\left(1-\rho_{2}\right)\left(\underline{p}_{2}^{e}+\frac{1}{2}(1-\theta)^{2}\right)+s\right]+\left(1-\rho_{1}\right)\left[\underline{p}_{1}^{e}+\frac{1}{2} \theta^{2}\right] \\
E\left[c_{1}^{E G}\right] & =\rho_{1}\left[\rho_{2}\left(\bar{p}_{1}^{e}+\frac{1}{2} \theta^{2}\right)+\left(1-\rho_{1}\right)\left(\underline{p}_{2}^{e}+\gamma+\frac{1}{2} \theta^{2}\right)+s\right]+\left(1-\rho_{1}\right)\left[\underline{p}_{1}^{e}+\frac{1}{2} \theta^{2}\right] \\
E\left[c_{2}^{E S}\right] & =\rho_{2}\left[\rho_{1}\left(\bar{p}_{2}^{e}+\frac{1}{2}(1-\theta)^{2}\right)+\left(1-\rho_{1}\right)\left(\underline{p}_{1}^{e}+\frac{1}{2} \theta^{2}\right)+s\right] \\
& +\left(1-\rho_{2}\right)\left[\underline{p}_{2}^{e}+\frac{1}{2}(1-\theta)^{2}\right] \\
E\left[c_{2}^{E S}\right] & =\rho_{2}\left[\rho_{1}\left(\bar{p}_{2}^{e}+\frac{1}{2}(1-\theta)^{2}\right)+\left(1-\rho_{1}\right)\left(\underline{p}_{1}^{e}+\gamma+\frac{1}{2}(1-\theta)^{2}\right)+s\right] \\
& +\left(1-\rho_{2}\right)\left[\underline{p}_{2}^{e}+\frac{1}{2}(1-\theta)^{2}\right] .
\end{aligned}
$$

Note that symmetry with respect to expected prices and probabilities, i.e. $\bar{p}_{1}^{e}=\bar{p}_{1}^{e}, \underline{p}_{1}^{e}=\underline{p}_{2}^{e}$ and $\rho_{1}^{e}=\rho_{2}^{e}$, and solving $E\left[c_{1}^{E S}\right]=E\left[c_{2}^{E S}\right]$ and $E\left[c_{1}^{E G}\right]=E\left[c_{2}^{E G}\right]$ for $\theta$ leads to the same solution $\theta^{N I}(\cdot)$. Furthermore, given that actual prices are given by $\bar{p}_{i}>\underline{p}_{j}$, the uninformed consumers that are just indifferent between using the price guarantee and switching to the firm with the lower price are given by

$$
\widetilde{\theta}_{1}^{N I G}\left(\bar{p}_{1}, \underline{p}_{2}\right)=\frac{1}{2}-\gamma \text { and } \widetilde{\theta}_{2}^{N I G}\left(\bar{p}_{2}, \underline{p}_{1}\right)=\frac{1}{2}+\gamma .
$$

The expected profit of firm 1 can now be written as

$$
\begin{aligned}
& \pi_{1}^{e}\left(\bar{p}_{1}\right)=\bar{p}_{1} \rho_{2} \theta^{I}\left(\bar{p}_{1}, \bar{p}_{2}\right)+\underline{p}_{2}\left(1-\rho_{2}\right)\left(\nu \theta^{I}\left(\bar{p}_{1}, \underline{p}_{2}\right)+(1-\nu) \widetilde{\theta}_{1}^{N I G}\left(\bar{p}_{1}, \underline{p}_{2}\right)\right) \\
& \pi_{1}^{e}\left(\underline{p}_{1}\right)=\underline{p}_{1}\left[\rho_{2}\left(\nu \theta^{I}\left(\underline{p}_{1}, \bar{p}_{2}\right)+(1-\nu) \widetilde{\theta}_{2}^{N I G}\left(\bar{p}_{2}^{e}, \cdot\right)\right)+\left(1-\rho_{2}\right)\left(\nu \theta^{I}\left(\underline{p}_{1}, \underline{p}_{2}\right)+(1-\nu) \theta^{N I}(\cdot)\right)\right] .
\end{aligned}
$$

Using the respective expressions for firm 2, restricting the analysis to symmetry, i.e. $\bar{p}_{1}^{e}=\bar{p}_{1}^{e}$ and $\underline{p}_{1}^{e}=\underline{p}_{2}^{e}$ as well as $\rho=\rho_{1}=\rho_{2}$, the solutions of the first order conditions are given by

$$
\bar{p}^{*}=\frac{1}{2} \text { and } \underline{p}^{*}=\frac{1+2 \gamma \rho}{2(1-\rho) \nu} .
$$

Thus, we also have

$$
\bar{p}^{*}-\underline{p}^{*}<0
$$

which shows that the proposed equilibrium does not exists. 